\title{
Calcium Aluminate Cement Blends Containing Bioactive Glass and Strontium for Biomaterial Applications
}

\author{
A.M. Barbosa ${ }^{a}$, K.W. dos Santos ${ }^{a}$, I. S. Gonçalves ${ }^{a}$, P.M.S.C.M. Leite ${ }^{a}$, A.S. Martorano ${ }^{b}$, G. Grisote ${ }^{c}$,

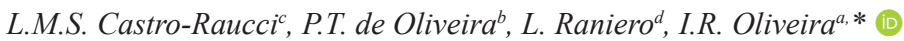 \\ ${ }^{a}$ Universidade do Vale do Paraiba, Instituto de Pesquisa e Desenvolvimento, \\ São José dos Campos, SP, Brasil. \\ ${ }^{b}$ Universidade de São Paulo, Faculdade de Odontologia de Ribeirão Preto, São Paulo, SP, Brasil. \\ ${ }^{c}$ Universidade de Ribeirão Preto, Faculdade de Odontologia, Ribeirão Preto, SP, Brasil. \\ ${ }^{d}$ Universidade do Vale do Paraíba, Laboratório de Nanosensores, São José dos Campos, SP, Brasil.
}

Received: May 13, 2021; Revised: August 14, 2021; Accepted: September 05, 2021.

In this work blends based on calcium aluminate cement (CAC) containing bioactive glass (BG) $(5,7.5$ and $10 \mathrm{wt} \%)$ and strontium oxide $(1 \mathrm{wt} \%)$ were produced aiming improve their bioactivity and the capacity to stimulate the bone regeneration. In the first part, the blends containing only BG were characterized as theoretical density, microhardness, uniaxial cold crush strength after SBF and apparent porosity and pore size distribution before and after SBF treatment. In the second part, bioactivity and cell culture tests were also conducted in the blends containing BG and strontium oxide. The addition of $7.5 \mathrm{wt} \%$ of BG in homogeneous calcium aluminate cement $(\mathrm{CH})$ improved its mechanical properties as microhardness and uniaxial cold crushing strength. The blends were more bioactive due to the presence of a highly soluble amorphous phase as confirmed by means of SEM/EDX mainly for 7.5 wt $\%$ BG without and with Sr from 1 day in SBF. FTIR analyses indicated the formation the apatite-like phase by means of increase of intensity of the $\mathrm{PO}_{4}^{3-}$ peaks after SBF treatment. All blends allowed the development of the osteoblastic phenotype and the formation of mineralized matrix increased due to the inclusion of $\mathrm{BG}$ and $\mathrm{Sr}$ promoting the osteogenesis process.

Keywords: Calcium aluminate cement; Bioactive glass; Strontium, Bioactivity, In vitro tests.

\section{Introduction}

Disorders related to bone tissue can lead to bone loss, and often caused by inflammatory diseases, trauma, tumors or degenerative diseases. The main healthiness issue for this population is to improve quality of life, which is quite challenging for tissue engineering. In fact, this field aims to study and create biomaterials that can assist in the bone regeneration process, involving research in health sciences and biomaterials engineering ${ }^{1,2}$.

The biomaterials used to perform bone repair must be similar to real bone tissue properties, because as a rigid organ it has functions of great importance, such as to protect and support organs present in the body and facilitate locomotion $1^{1-3}$. In addition, the biomaterial to be implanted must be biocompatible ${ }^{4}$.

Among the biomaterials reported in scientific researches as a potential substitute in bone repairing, calcium aluminate cement (CAC) has been heightened for its physical, mechanical, and biocompatibility properties ${ }^{5,6}$. This material presents unique characteristics of curing, hardening, related microstructure ${ }^{2,6,7}$, and thermal expansion coefficient which are very similar to that of human bone ${ }^{8,9}$. Also, CAC develops an appreciable mechanical strength at room temperature and

*e-mail: ivoneregina.oliveira@gmail.com it has shown to improve their bioactivity when combined with others compounds as hydroxyapatite ${ }^{6,10}$.

Although CAC is reliable for many applications, another material that stands out among the main bioceramics is the bioactive glass $(\mathrm{BG})^{11,12}$. BG represents one of the most promising bone repair materials, due to its excellent biocompatibility, osteoinductivity, bioactivity, higher amount of calcium and phosphorus in its chemical composition compared to ordinary glass as well as bactericidal capacity ${ }^{13-15}$. In addition, it has the ability to chemically bond to bone tissues, forming a layer of apathy on its surface when exposed to physiological fluids, exhibiting excellent bioactivity, which can be explained by the similarity between the composition and the structure of the bioactive materials with the mineral phase of the bone ${ }^{14}$.

In order to increases the BG interaction with body fluids, the BG powder can be used in several medical and dental applications, accelerating the regeneration of injured tissues of the human body, such as bone fractures, skin wounds, problems in the cartilage, enamel, and dentin of the teeth, and even nerves. On the other hand, the disadvantages of bioactive glass are its low fracture toughness and mechanical strength ${ }^{16}$. Thus, the mechanical reliability of pure bioactive glass is not enough, especially in humid environments, as it cannot be used as implants that require a heavy load, such as teeth or bone. 
Another bioactive factor that has been studied to stimulate the regeneration of injured tissue is strontium $\left(\mathrm{Sr}^{2+}\right)$, suggesting that low doses of strontium salts increase bone formation ${ }^{17,18}$. This metal is highly similar to calcium in terms of physico-chemical and biological aspects, in addition to not presenting levels of toxicity to human health. Its main route of bioaccumulation is the mineralized phase of bone tissue, preferably in the cortical bone.

Interest in the effects of strontium on bone has increased dramatically in the past decade due to the development of the promising drug strontium ranelate. This medicine is used to treat osteoporosis, one of the main bone diseases that affects hundreds of millions of people worldwide, especially postmenopausal women. The novelty of strontium ranelate, compared to other treatments for osteoporosis, is its unique effect on bone: it simultaneously promotes bone formation by osteoblasts and inhibits bone resorption by osteoclasts. In addition to affecting bone cells, treatment with strontium ranelate also has a direct effect on the mineralized bone matrix $^{18}$.

In this context, the aim of this work is produce blends based on CAC containing BG and strontium oxide, expecting to improve their bioactivity and the capacity to stimulate the bone regeneration.

The development of this study comprehends the synthesis of BG-58S through the sol-gel route. In the first part, blends were prepared by mixing CAC with different content of BG$58 \mathrm{~S}(5,7.5$ e $10 \mathrm{wt} \%)$ and these blends were characterized as theoretical density, microhardness, uniaxial cold crush strength after SBF and apparent porosity and pore size distribution before and after SBF treatment. In the second part, bioactivity and cell culture tests were also conducted in the blends mentioned above in which $1 \mathrm{wt} \%$ of strontium oxide were added.

\section{Experimental Procedures}

\subsection{Synthesis and characterization of bioactive glass}

Bioactive glass (BG-58S) with a composition in the ternary system $58 \mathrm{SiO}_{2}-33 \mathrm{CaO}-9 \mathrm{P}_{2} \mathrm{O}_{5}(\mathrm{wt} \%)$ was prepared using as precursors high-purity reagents: $\mathrm{SiO}_{2}$ (Tetraethylorthosilicate, TEOS, $\mathrm{Si}\left(\mathrm{OC}_{2} \mathrm{H}_{5}\right)_{4}, 98 \%$, Sigma-Aldrich); $\mathrm{CaO}$ (calcium nitrate, $\mathrm{Ca}\left(\mathrm{NO}_{3}\right)_{2} \cdot 4 \mathrm{H}_{2} \mathrm{O}, 99 \%$, Labsynth) and $\mathrm{P}_{2} \mathrm{O}_{5}$ (Triethylphosphate, TEP, $\left(\mathrm{OP}\left(\mathrm{OC}_{2} \mathrm{H}_{5}\right)_{3} ; \geq 99.8 \%\right.$, Sigma-Aldrich).

BG-58S was synthesized via sol-gel method at room temperature and the gelation reaction was catalyzed by the addition of ammonium hydroxide solution $\left(\mathrm{NH}_{4} \mathrm{OH}, 28\right.$ $30 \%$, Fmaia Gold). TEOS, distilled water, and $2 \mathrm{M}$ nitric acid $\left(\mathrm{HNO}_{3}, 65 \%\right.$, Neon) were added to ethanol $(99.8 \%$, Neon) and stirred at room temperature for $30 \mathrm{~min}$. TEP was then added into the prepared acid silica sol. After stirring for $20 \mathrm{~min}$, the $\mathrm{Ca}\left(\mathrm{NO}_{3}\right)_{2} \cdot 4 \mathrm{H}_{2} \mathrm{O}$ was completely dissolved into the acid sol maintaining stirring for $20 \mathrm{~min}$. Ammonia solution ( $2 \mathrm{M}$ ) was dropped into the acid sol while vigorously stirring. The obtained gel was stirred by muddler and kept in the oven at $60{ }^{\circ} \mathrm{C}$ for 24 hours to remove the residual water and ethanol. The dry gel powder was macerated and calcined at $550^{\circ} \mathrm{C}$ in air for 2 hours $\left(3^{\circ} \mathrm{C} / \mathrm{min}\right)$. The resulting powder was macerate and characterized as particle size distribution using an S3550 analyzer (Microtrac) obtaining particles with $\mathrm{D}_{50} \sim 4 \mu \mathrm{m}$.

\subsection{Preparation and characterization of calcium aluminate cement containing bioactive glass and strontium}

The calcium aluminate cement (CAC) was a mixture of the $\mathrm{CA}\left[\mathrm{CaAl}_{2} \mathrm{O}_{4}\right]$ and $\mathrm{CA}_{2}\left[\mathrm{CaAl}_{4} \mathrm{O}_{7}\right]$ phases at molar ratio $1: 1$ and $\mathrm{D}_{50} \sim 8 \mu \mathrm{m}$. It is worth mentioning that the level of Al-leakage from CAC is very low and no potential toxicity due to this ion should be expected. Besides that, this material is basic on its chemical nature and all Al-ions will be as $\mathrm{Al}(\mathrm{OH})_{4}{ }^{-}$which has its diffusivity decreased in the matrix ${ }^{8,19}$

In this work, a dispersant Castament FS60 at $0.6 \mathrm{wt} \%$ (BASF, Germany) and a plasticizer $\mathrm{CaCl}_{2} \cdot 2 \mathrm{H}_{2} \mathrm{O}$ t $2.8 \mathrm{wt} \%$ (Labsynth, Brazil) were added to CAC and mixed using a dry-ball mixing for one hour to form a homogeneous cement $(\mathrm{CH})$. In the first part, blends were prepared by mixing $\mathrm{CH}$ with different content of BG-58S using dry-ball mixing for one hour resulting in the following groups: (1) $\mathrm{CH}$; (2) $\mathrm{CH}-5 \mathrm{BG}(\mathrm{CH}-5 \mathrm{wt} \%$ BG-58S); (3) CH-7.5BG (CH$7.5 \mathrm{wt} \% \mathrm{BG}-58 \mathrm{~S})$ and (4) CH-10BG (CH-10 wt $\%$ BG-58S). The mixtures were used to prepare aqueous suspensions containing $75 \mathrm{wt} \%$ solids and molded in cylindrical molds (diameter $=6 \mathrm{~mm}$ and height $=2 \mathrm{~mm}$ ) to theoretical density and microhardness analyses. Another set of samples (diameter $=16 \mathrm{~mm} \times$ height $=18 \mathrm{~mm}$ ) were molded for the tests of apparent porosity, pore size distribution and resistance to uniaxial compression. The samples were cured in a saturated environment at $37^{\circ} \mathrm{C}$ for 5 hours.

The theoretical or real density of the samples, previously dried at $110{ }^{\circ} \mathrm{C}$ for 24 hours, was evaluated via helium pycnometry technique (Ultrapyc 1200e, V5.04). Density values were expressed as the mean of twenty measurements taken from each blend.

The microhardness test was carried out in Vickers FV-100e by using samples dried at $110{ }^{\circ} \mathrm{C}$ for 24 hours. Microhardness values were expressed as the mean of the five indentations of each sample using loads of 98.07 N.m.

The samples were demolded and dried at $110{ }^{\circ} \mathrm{C}$ for another $24 \mathrm{~h}$ after curing period. Apparent porosity and pore size distribution measurements were carried out in dried materials, which were classified as "without the SBF treatment" tests. Other cast cylinders were also placed in contact with simulated body fluid (SBF) solution at $37^{\circ} \mathrm{C}$ for 7 days. Humid samples were then subjected to uniaxial compression tests, whereas others were dried at $110{ }^{\circ} \mathrm{C}$ for $24 \mathrm{~h}$ and their apparent porosity and pore size distribution were evaluated and denominated as "with the SBF treatment". SBF solution is often used and indicated for in vitro evaluations of the formation of apatite surface layers on materials according to ISO $23317^{20}$.

Apparent porosity (AP) was measured via the Archimedes method (ASTM C830). The samples masses, dried $\left(\mathrm{M}_{\mathrm{s}}\right)$, immersed $\left(\mathrm{M}_{\mathrm{i}}\right)$ obtained by keeping the samples for $1 \mathrm{~h}$ under vacuum in kerosene $\left(\rho=0.8 \mathrm{~g} / \mathrm{cm}^{3}\right)$ and humid $\left(M_{u}\right)$ were used in Equation 1:

$A P=\left[\frac{\left(M_{u}-M_{S}\right)}{\left(M_{u}-M_{i}\right)}\right] x 100$ 
where, $M_{u}$ is the mass of the wet sample, $M_{s}$ is the mass of the dry sample and $M_{i}$ is the mass of the sample when immersed in the liquid.

Pore size distribution of the samples was measured through the mercury intrusion porosimetry technique (Autopore IV 9500 equipment, Micromeritics, USA). The mercury volume that penetrates the pores is directly measured as a function of the applied pressure. This method is based on the Washburn equation (Equation 2).

$$
D=4 \gamma P^{-1} \cos \phi
$$

where $\mathrm{D}$ is the pore diameter, $\mathrm{P}$ is the applied pressure $(\mathrm{Pa}), \gamma$ is the mercury surface tension $\left(\mathrm{J} / \mathrm{m}^{2}\right)$ and $\phi$ is the contact angle assumed to be $\left(130^{\circ}\right)$ between the mercury and the sample.

Uniaxial cold crushing strength tests (ISO 9917-1) were carried out under a crosshead rate of $0.15 \mathrm{~mm} / \mathrm{min}$ in mechanical testing equipment (DL 10000, EMIC, Brazil). The uniaxial cold crushing strength $\left(\sigma_{R}, \mathrm{MPa}\right)$ was calculated as follows:

$$
\sigma_{R}=\left[\frac{4 P}{\pi D^{2}}\right]
$$

where, $P(\mathrm{~N})$ is the maximum load applied and $\mathrm{D}(\mathrm{mm})$ is the mean diameter of the sample.

In the second part, blends were also prepared by adding strontium oxide ( $\mathrm{SrO}, 99.9 \%$, Sigma-Aldrich) to compositions containing different content of BG-58S resulting in the additional groups: (5) $\mathrm{CH}-5 \mathrm{BG} / \mathrm{Sr}$ (CH-5 wt\% BG-58S-1 wt\% SrO); (6) $\mathrm{CH}-7.5 \mathrm{BG} / \mathrm{Sr}(\mathrm{CH}-7.5 \mathrm{wt} \% \mathrm{BG}-58 \mathrm{~S}-1 \mathrm{wt} \% \mathrm{SrO})$ and (7) $\mathrm{CH}-10 \mathrm{BG} / \mathrm{Sr}$ (CH-10 wt \% BG-58S-1 wt \% SrO). All groups were used to prepare aqueous suspensions containing $75 \mathrm{wt} \%$ solids and molded in cylindrical molds (diameter $=6 \mathrm{~mm}$ and height $=2 \mathrm{~mm}$ ) to bioactivity evaluation while their dry powder mixtures were previously sterilized at $120{ }^{\circ} \mathrm{C}$ for 2 hours and used in cell culture tests.

For bioactivity tests, the samples in duplicate for each blend were immersed in $19 \mathrm{~mL}$ of SBF solution in polyethylene containers maintained continuously shaken at $100 \mathrm{rpm}$ at $37.0^{\circ} \mathrm{C}$ using an incubator shaker (MA420, Marconi) for 1, 7, and 15 days. Afterward, the samples were filtered and washed with deionized water and acetone to remove the solution and to halt any surface reaction. Shortly after drying at room temperature for 3 days, samples were evaluated by scanning electron microscopy (SEM, EVO MA10 Zeiss) with energy dispersive X-ray analysis (EDX), X-ray diffraction (XRD-6000, Shimadzu), Fourier transform infrared spectroscopy (FTIR, PerkinElmer, Spectrum 400) in the range of 2000 to $450 \mathrm{~cm}^{-1}$, before and after immersion in SBF. A surface area to volume ratio of $0.1 \mathrm{~cm}^{-1}$ was maintained for all immersions, and the SBF solutions were not exchanged during the experiments.

\subsection{Cell culture tests}

Osteoblast like cells MC3T3-E1 (subclone 14, CRL-2594, American Type Culture Collection-ATCC, Manassas, VA, USA) were thawed and grown in $75 \mathrm{~cm}^{2}$ bottles (Corning Inc., Corning, New York, NY, USA) with expansion medium, composed of $\alpha$-MEM (Invitrogen, Grand Island, NY, USA), $10 \%$ FBS (Fetal Bovine Serum, Invitrogen) and $100 \mathrm{IU} /$
mL-100 ug/mL penicillin-streptomycin (Sigma-Aldrich). After subconfluence, the cells were counted and plated at a density of 10.000 cells $/ \mathrm{cm}^{2}$ directly into polystyrene plate wells (Corning Inc.), and cultured in osteogenic medium (composed of the expansion medium plus $7 \mathrm{mM}$ -glycerophosphate and $50 \mu \mathrm{g} / \mathrm{mL}$ ascorbic acid) and allowed to adhere for 24 hours prior to exposure to the extract of the evaluated compositions. During the entire cultivation period, the cells were kept at $37^{\circ} \mathrm{C}$, in a humid atmosphere containing $5 \% \mathrm{CO}_{2}$ and $95 \%$ atmospheric air, the culture media were changed every 3 days.

$0.2 \mathrm{~cm}^{3}$ of each composition was used to fill the bottom of the 24-well plate wells and, after initial setting, the cements were conditioned with $1.9 \mathrm{~mL}$ of the serum-free osteogenic medium $\left(1 \mathrm{~mL} / \mathrm{cm}^{2}\right)$ for 24 hours, at a temperature of $37{ }^{\circ} \mathrm{C}$, in a humid atmosphere containing $5 \% \mathrm{CO}_{2}$ and 95\% atmospheric air. After this period, the culture medium used for conditioning was collected, filtered and stored at $-20^{\circ} \mathrm{C}$ until use in the experiments. For the exposure of cell cultures, the extract of each of composition was thawed at room temperature and diluted in the proportions of 50; 25 and $12.5 \%$ in osteogenic medium, with fetal bovine serum (Invitrogen) being added in a final concentration of $10 \%$. Cultures exposed only to the osteogenic medium served as Control. After 3 days, cell viability was qualitatively assessed using the Live/Dead commercial kit (Viability/Cytotoxicity, for mammalian cells, Molecular Probes Inc, Eugene, OR, USA), following the manufacturer's instructions. Viable cells were marked with green fluorescence by the reaction of calcein $\left(\mathrm{C}_{30} \mathrm{H}_{26} \mathrm{~N}_{2} \mathrm{O}_{13}\right)$ with intracellular esterases, while dead cells were marked with red fluorescence by binding ethidium homodimer-1 (EthD-1) to the nucleic acids exposed with the rupture of the cell membranes (cell death). The images were obtained in a trilocular inverted microscope, by direct fluorescence (Led B-G-U-UV Trinocular, Digilab, Piracicaba, SP, BR), with a Nikon digital camera attached.

Viability/cytotoxicity was also quantitatively assessed through mitochondrial activity after 48 and 72 hours of exposure to cements, using the MTT colorimetric assay $\{[3-$ (4,5-dimethylthiazol-2-yl) -2,5- bromide difeniltetrazolio]\} (Sigma-Aldrich), a salt that is reduced by mitochondrial proteinases, active only in viable cells. Aliquots of MTT at $5 \mathrm{mg} / \mathrm{mL}$ in PBS were prepared and the primary cultures were then incubated with this $10 \%$ solution in culture medium for 4 hours at $37^{\circ} \mathrm{C}$ in a humidified atmosphere containing $5 \% \mathrm{CO}_{2}$ and $95 \%$ atmospheric air. After that period, the cultures were washed with $1 \mathrm{ml}$ of heated PBS. Then, $1 \mathrm{ml}$ of acid isopropanol solution (100 $\mathrm{ml}$ of isopropanol and $134 \mu \mathrm{L}$ of $\mathrm{HCl}$ ) was added to each well under stirring for $5 \mathrm{~min}$, for complete solubilization of the precipitate formed. $200 \mu \mathrm{L}$ aliquots were removed from the wells and transferred to a 96-well plate for colorimetric measurement in a spectrophotometer $(570 \mathrm{~nm} ; \mu$ Quanti, BioTek Instruments, Inc., Winooski, VT, USA).

At 7 days, a test was carried out for the qualitative assessment of ALP activity, by marking with Fast Red. The culture medium was removed and the wells were washed with PBS solution (Phosphate-Buffered Saline, Invitrogen) heated to $37^{\circ} \mathrm{C} .1 \mathrm{~mL} /$ well of $120 \mathrm{mMTris}$ buffer solution (Sigma-Aldrich) with pH 8.4 was added, containing $1.8 \mathrm{mM}$ 
Fast Red TR (Sigma-Aldrich), 0.9 mMnaphthol-ASMXphosphate (Sigma-Aldrich) and 1:9 of dimethylformamide (Merck KGaA, Darmstadt, HE, DE) and the plates were kept for $30 \mathrm{~min}$ in a humid atmosphere containing 5\% $\mathrm{CO}_{2}$ and $95 \%$ atmospheric air. The images were obtained in a trilocular inverted microscope, by direct fluorescence (Led BGU-UV Trinocular, Digilab, Piracicaba, SP, BR), with a Nikon digital camera attached.

At 14 days, cultures were washed in PBS (Invitrogen) solution, fixed in $70 \%$ ethyl alcohol at $4^{\circ} \mathrm{C}$ for $60 \mathrm{~min}$ and washed in PBS (Invitrogen) and double-distilled water. Subsequently, they were stained with $2 \%$ Alizarin red (SigmaAldrich), $\mathrm{pH} 4.2$ at room temperature (RT) for 15 minutes, again washed with PBS (Invitrogen), deionized water and the plates were allowed to dry at room temperature $\left(\approx 25^{\circ} \mathrm{C}\right)$. Macroscopic images of the wells were obtained with a MZ6 stereomicroscope (Leica, Wetzlar, LD, DE), in a final 8X magnification, using a DC300 F camera (Leica) with 1.3 Mega Pixel resolution. The biochemical quantification of the mineralization was performed by the colorimetric method, according to which $360 \mu \mathrm{L}$ of $10 \%$ acetic acid was added to each well and the plate was taken to the shaker for $30 \mathrm{~min}$ at room temperature $\left(\approx 25^{\circ} \mathrm{C}\right)$. The content of each well was transferred to Eppendorf Tubes (Eppendorf,
Hamburg, HA, DE) and then heated to $85^{\circ} \mathrm{C}$ for $10 \mathrm{~min}$ and, subsequently, kept on ice for $5 \mathrm{~min}$. The tubes were centrifuged at $10,500 \mathrm{~g}$, at $23^{\circ} \mathrm{C}$, for $15 \mathrm{~min}$. Then, $100 \mu \mathrm{L}$ of the supernatant, formed after the centrifugation process, was transferred to a new set of Eppendorf tubes (Eppendorf). Then, $40 \mu \mathrm{L}$ of $10 \%$ ammonium hydroxide was added to neutralize the acid, and the entire contents $(140 \mu \mathrm{L})$ were transferred to a 96-well plate (Corning Inc.). Absorbance was measured using a spectrophotometer (405 nm, Epoch 2).

The quantitative data were submitted to non-parametric Kruskal-Wallis test, followed by Student-Newman-Keuls post-test, when appropriate $(\alpha=5 \%)$, analyzed through SigmaPlot (Systat Software Inc., SJ, USA).

\section{Results and Discussion}

In the first part, the present study focused on assessing the influence of BG addition on some properties of calcium aluminate cement. Characterization results of theoretical or real density, mechanical properties and apparent porosity recorded for calcium aluminate cement blends containing bioactive glass $(5,7.5$ and $10 \mathrm{wt} \%)$ are shown in Figure 1. It is possible noticing that the addition of BG-58S powder to homogeneous cement $(\mathrm{CH})$ influences significantly its mechanical properties.
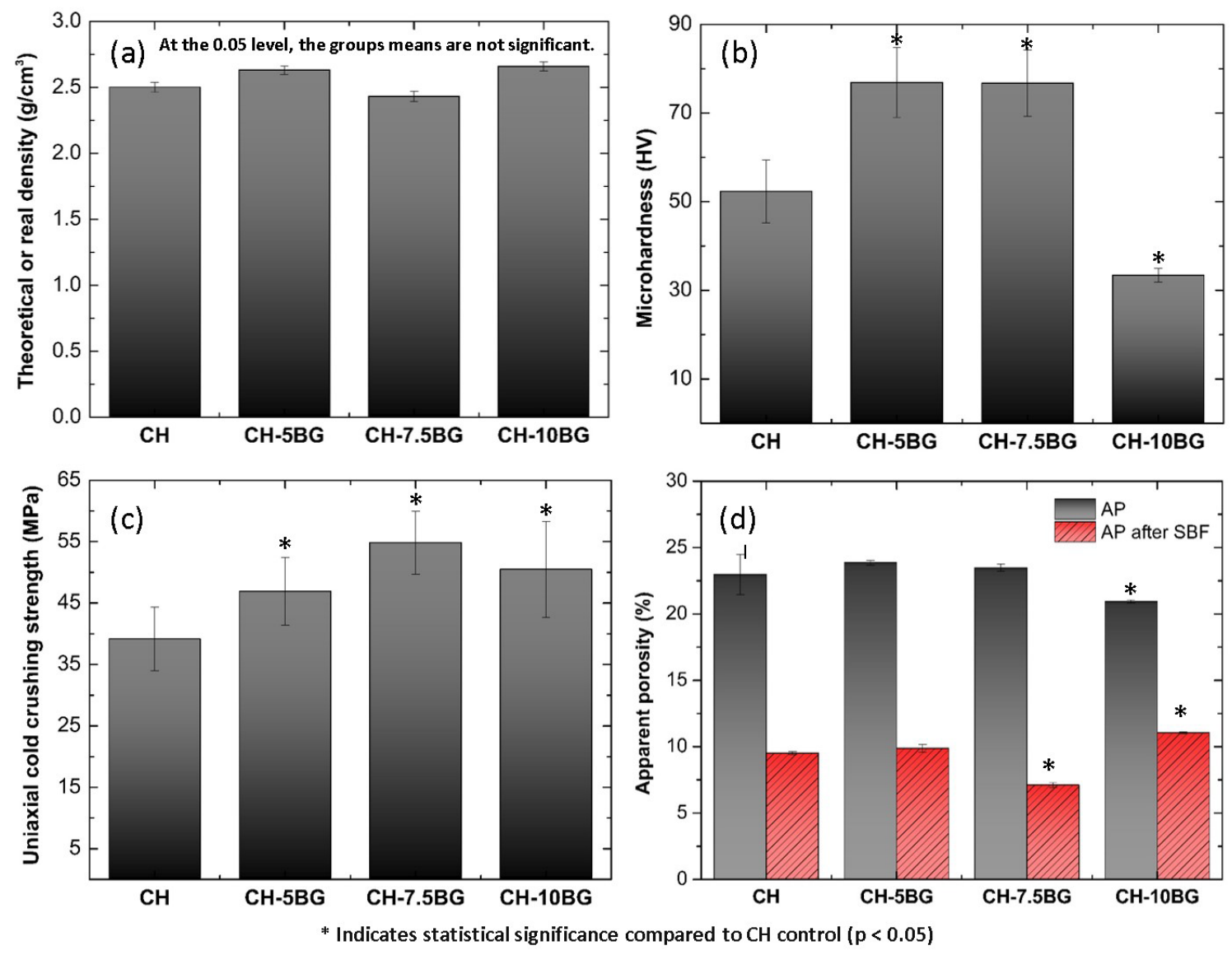

Figure 1. (a) Theoretical or real density; (b) microhardness; (c) uniaxial cold crushing strength after SBF treatment and (d) apparent porosity before and after SBF treatment for blends based on homogeneous calcium aluminate cement $(\mathrm{CH})$ containing different contents of bioactive glass (BG). 
The results presented in Figure 1a show that the addition of $\mathrm{BG}$ to $\mathrm{CH}$ has not significant differences compared to the theoretical density of pure $\mathrm{CH}$ independently of the content of BG.

The blends present higher average values compared to the spongy bone tissue $\left(1.25 \mathrm{~g} / \mathrm{cm}^{3}\right)$ and cortical bone tissue $\left(1.92 \mathrm{~g} / \mathrm{cm}^{3}\right)^{21}$. However, when looking at Figure $1 \mathrm{~b}$ and analyzing the results found for microhardness, it can be seen that $\mathrm{CH}$ has its microhardness improved by adding up to $7.5 \%$ of BG (with statistical significance), indicating that there was a good adhesion of BG in the cement matrix. The addition of higher levels of $\mathrm{BG}$ led to a reduction in microhardness. The composition with $10 \%$ BG became more viscous and more BG was noted on the surface of the samples, so the microhardness test for evaluating the resistance to a localized plastic deformation may have been more influenced by the added glass phase, due to its lower mechanical strength compared to $\mathrm{CH}$. In this case, the value obtained was below that verified for cortical (44.60) and trabecular tissues $(44.66)^{22}$.

The results obtained for uniaxial cold crushing strength after SBF treatment, Figure 1c, showed that the behavior of $\mathrm{CH}\left(\mathrm{D}_{50} \sim 8 \mu \mathrm{m}\right)$ has significantly improved with the BG $\left(\mathrm{D}_{50} \sim 4 \mu \mathrm{m}\right)$ addition. The presence of two or more raw materials in a cement-based mixture affects the rheological properties and particle packing of the system. Fine powders tend to fill in the voids among the large particles of the mixture decreasing the porosity level of the prepared samples depending on the features and content of the additives incorporated into the calcium aluminate cement. Thus, the blend $10 \%$ of BG presented decreased in apparent porosity before SBF treatment (Figure 1d).

The blends $7.5 \%$ of BG (55 MPa) and $10 \%$ of BG $(50 \mathrm{MPa})$ had the uniaxial compression close to the lowest value registered to the cortical human bone with uniaxial compression in the range of 52-196 $\mathrm{MPa}^{23,24}$. It is important that the biomaterial used for bone repair present mechanical strength near to bone in order to support the same stress levels. The concentration of stress above the limit of the material can cause defects as micro-fractures and consequently favor bacterial proliferation, infiltration, and material displacement.
The observed increases in the strength of these blends can also be correlated to the significant drop in apparent porosity observed after treatment with SBF, as shown in Figure 1d.

According to the previous studies ${ }^{18,25,26}$ the significant drop in apparent porosity observed after treatment with SBF can be explained by the presence of precipitates on the surface of the materials. Thus, the same effect should take place for the plain $\mathrm{CH}$ and blends with $\mathrm{BG}$ in the present work. The interaction of these biomaterials with the ions available in the SBF solution promotes the formation of precipitates, which covers the solid surface and fills the pores, reducing their apparent porosity. This effect was more significant for the blend $7.5 \%$ of BG compared to the $10 \%$ of BG one. This behavior may be associated to the fact the blend $10 \%$ of BG presents lower porosity before SBF and consequently less pores to be fill by the precipitates.

Another consequence observed by these authors is that overall pore size of the biomaterials is lower after SBF treatment when compared to the materials only placed in contact with water. Pore size distribution ( $\mathrm{dV} / \mathrm{d} \log \mathrm{d})$ results without or with the SBF treatment for calcium aluminate cement blends containing bioactive glass $(5,7.5$ and $10 \mathrm{wt} \%)$ are shown in Figure 2. All samples showed reduced apparent porosity and lower pore diameter after the SBF treatment indicating the formation of precipitates that closes the pores. After SBF treatment pores higher than $0.2 \mu \mathrm{m}$ are no longer observed.

In the second part, the present study focused on bioactivity and cell culture tests in the blends containing BG and strontium oxide. The presence of precipitates on the surface of the materials due to the reaction between their surfaces with the ions available in the SBF solution indicates their bioactivity. Bioactivity is defined as the material's ability to generate a carbonated hydroxyapatite layer on its surface in order to induce strong interfacial bonds with living tissues ${ }^{27}$.

The precipitate formation on sample surface can be observed through micrographs of the SEM as shown in Figure 3 for blends based on homogeneous calcium aluminate cement $(\mathrm{CH})$ containing different contents of bioactive glass (BG), without or with SBF treatment. The SBF treatment promoted changes on the surface of samples as a function of time when compared to samples before treatment. The formation
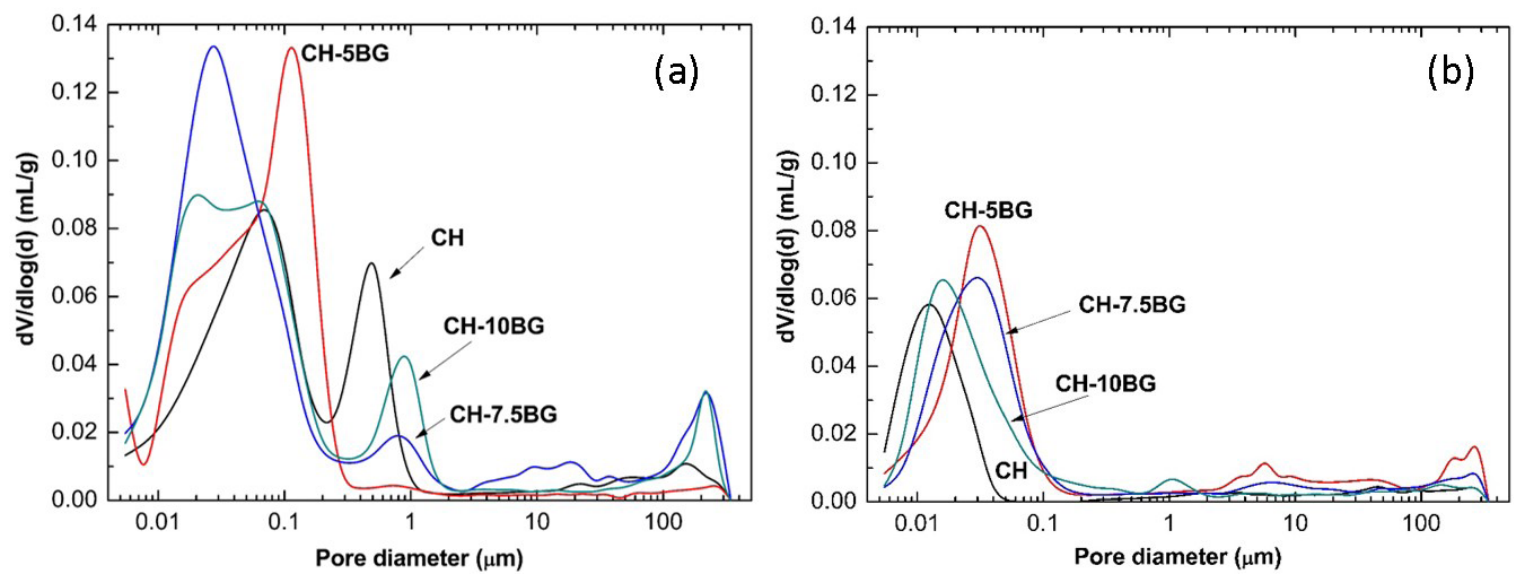

Figure 2. Pore size distribution (a) without or (b) with SBF treatment for blends based on homogeneous calcium aluminate cement $(\mathrm{CH})$ containing different contents of bioactive glass (BG). 


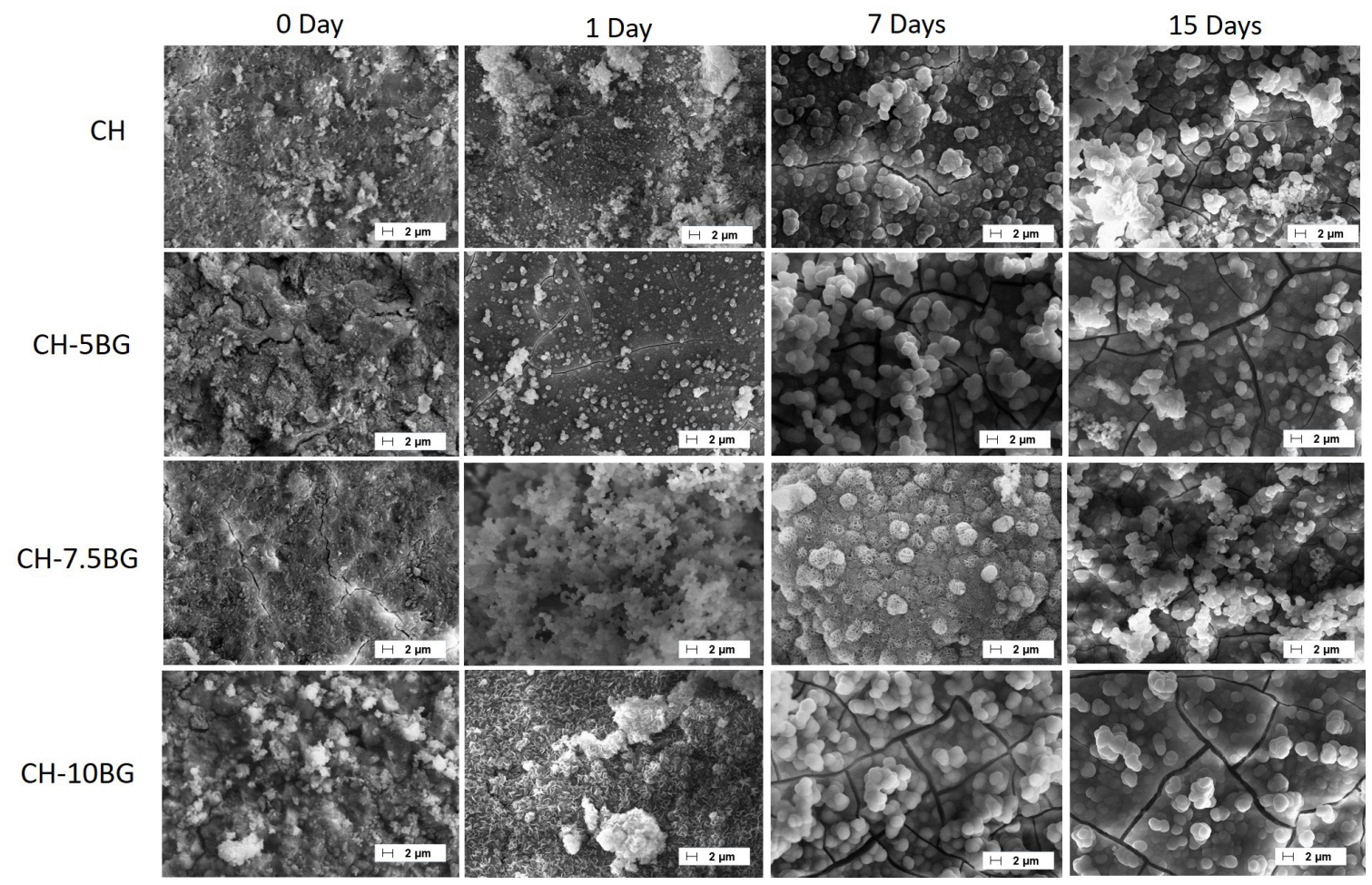

Figure 3. SEM micrographs for blends based on homogeneous calcium aluminate cement $(\mathrm{CH})$ containing different contents of bioactive glass (BG), without or with SBF treatment for 1, 7 and 15 days. The fractures in the newly developed layers were caused by the drying of the samples.

of a surface layer of precipitates after immersion in SBF occurred mainly for compositions with $7.5 \mathrm{wt} \% \mathrm{BG}$ from 1 day in SBF. This is indicative that the addition of BG to $\mathrm{CH}$ improved its bioactivity.

BG possesses excellent bioactivity promoting to chemically bond to bone tissues by means of an apatite layer on its surface when exposed to physiological fluids ${ }^{13,28-30}$.

BG suffers a sequence of chemical reactions when immersed in SBF which can explain their bioactivity mechanism. In the beginning, rapid exchange of $\mathrm{H}^{+}$ions from the physiological solution with modifiers cations ions present in its surface and thus, the silica groups hydrolyze leading to the formation of silanol bonds $(\mathrm{Si}-\mathrm{OH})$ on their surface. Then, more silanol bonds are formed because of the hydrolysis of $\mathrm{Si}-\mathrm{O}-\mathrm{Si}$ bonds due to a $\mathrm{pH}$ increase and it occurs the condensation and repolymerization of surface silanols to form $\mathrm{SiO}_{2}$-rich surface layer. This layer reacts with $\mathrm{Ca}^{2+}$ and $\mathrm{PO}_{4}^{3-}$ ions that migrate from the material and medium to the surface, inducing the formation of an amorphous calcium phosphate layer. Finally, it occurs the incorporation of hydroxide and carbonate ions from the medium and this amorphous layer progressively crystallizes into a biological reactive hydroxycarbonate apatite ${ }^{31-33}$. This carbonated hydroxyapatite layer is chemically and structurally equivalent to the bone mineral phase, favoring the chemical bonding between biomaterial and bone ${ }^{27}$.

Bioactive glass (BG) was also added in calcium aluminate cement $(5,7.5$ or $10 \mathrm{wt} \%)$ being verified increase in the amount of apatite formed after immersion in SBF with the increase of the amount of BG, mainly due to the high solubility of the amorphous phase ${ }^{34}$. Agglomerates of a $\mathrm{Ca}$, P-rich compound with spherical morphology were formed after 21 days. The formed compound was identified by DRX as hydroxyapatite (HA) on the samples containing 7.5 and $10 \mathrm{wt} \%$ of BG. The intensity of the peaks corresponding to $\mathrm{HA}$ increases as the $\mathrm{BG}$ content is increased, indicating that the material becomes more bioactive ${ }^{34}$.

The SEM micrographs obtained for blends based on homogeneous calcium aluminate cement containing different contents of bioactive glass (BG) and $1 \mathrm{wt} \%$ strontium $(\mathrm{Sr})$, without or with SBF treatment are shown in Figure 4. It is observed that the addition of $\mathrm{SrO}$ in the composition did not influence significantly the phase precipitation promoted by the addition of BG, maintaining the formation of a surface layer of precipitates mainly for blends with 7.5 and $10 \mathrm{wt} \%$ $\mathrm{BG}$ and $1 \mathrm{wt} \%$ strontium (Sr) from 1 day in SBF.

Table 1 shows EDX analyses of the blend's surfaces before and after the interaction with SBF for 1, 7 and 15 days. The formation of the $\mathrm{Ca}$ and $\mathrm{P}$-rich compound on the surface, which may correspond to apatite can indicate mainly by the increase of $\mathrm{P}$ in the EDX spectra after SBF. On the other hand, it is observed decrease in the aluminum content, which is one of the main chemical elements found in CAC.

The FTIR spectra of blends based on homogeneous calcium aluminate cement $(\mathrm{CH})$ containing different contents of bioactive glass (BG) and $1 \mathrm{wt} \%$ strontium $(\mathrm{Sr})$ before and after soaking in SBF solution for different time periods are shown in Figure 5. 


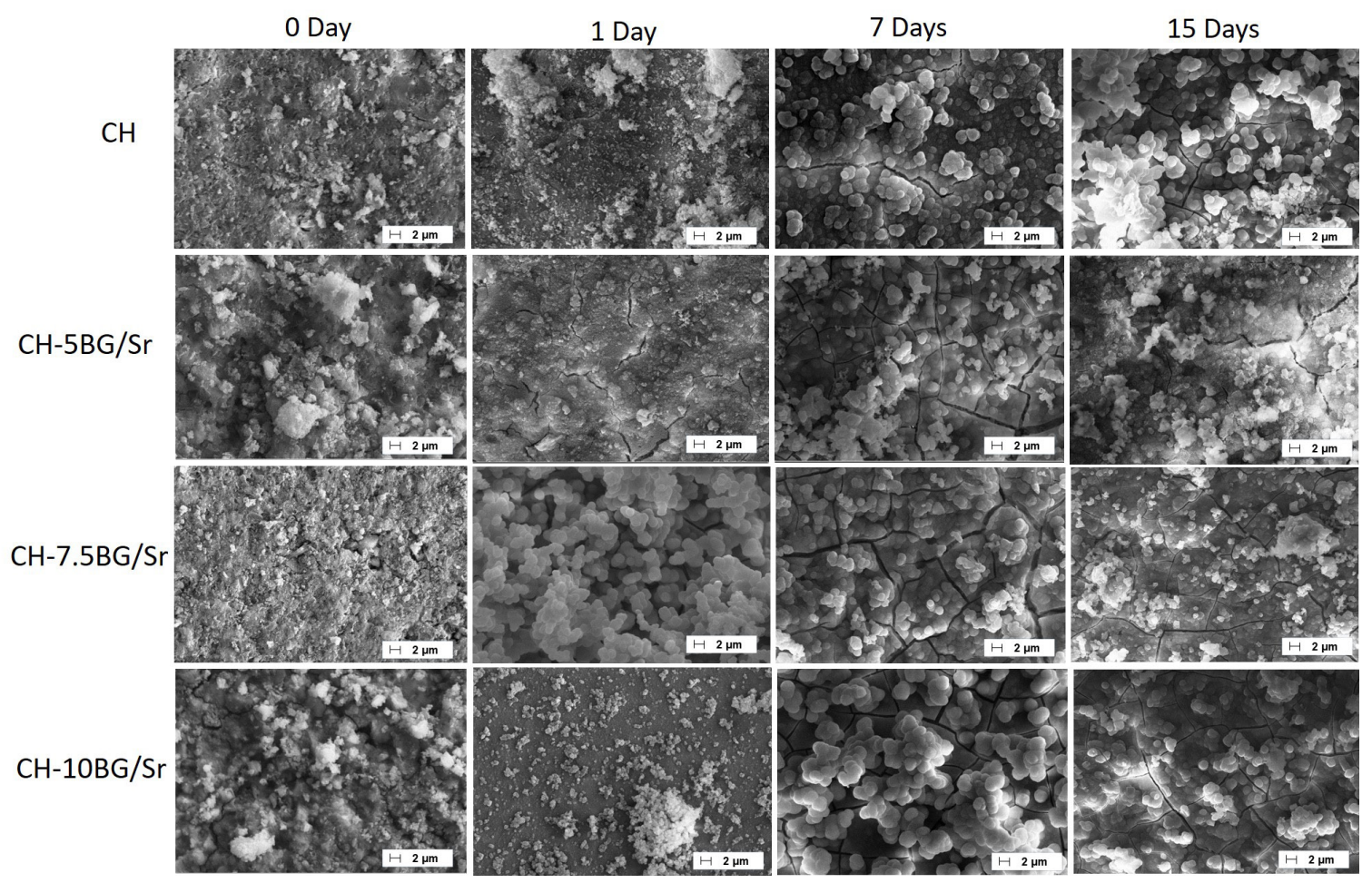

Figure 4. SEM micrographs for blends based on homogeneous calcium aluminate cement $(\mathrm{CH})$ containing different contents of bioactive glass (BG) and $1 \mathrm{wt} \%$ strontium (Sr), without or with SBF treatment for 1, 7 and 15 days. The fractures in the newly developed layers were caused by the drying of the samples.

The bands at $1029 \mathrm{~cm}^{-1}, 780 \mathrm{~cm}^{-1}$ and $533 \mathrm{~cm}^{-1}$ are assigned to the stretching and bending vibrations of the Al-O bonds of the hydrated cement ${ }^{35}$. The band at $1421-1433 \mathrm{~cm}^{-1}$ is the $\mathrm{C}-\mathrm{O}$ bond stretching of $\mathrm{CO}_{3}{ }^{2-}$, resulting from the carbonation of hydrated aluminate. Exposure of cement pastes to air results in a very quick carbonation.

Before soaking in SBF, the band in the spectrum (1000$1030 \mathrm{~cm}^{-1}$ ) also can correspond to the symmetric stretch of the bridged oxygen bond with silicon ( $\mathrm{Si}-\mathrm{O}-\mathrm{Si}$ ) due to $\mathrm{BG}$ addition ${ }^{36}$. After immersing in the SBF solution, the band at $800 \mathrm{~cm}^{-1}$ confirms the formation of $\mathrm{SiO}_{2}$ rich surface layer due to the dissolution of the glassy network. The intensity of the $\mathrm{PO}_{4}^{3-}$ peaks at the wave number $1030 \mathrm{~cm}^{-1}$ increased indicating the formation of the apatite-like phase ${ }^{37}$. The 872 and $1460 \mathrm{~cm}^{-1}$ bands could be assigned to a carbonate absorption band due to the reactivity of samples surface with $\mathrm{CO}_{2}$ from the atmosphere ${ }^{30,38-40}$. When compared with strontium-free blends, dissolution in the in the presence of strontium is reduced. The intensity of the $\mathrm{PO}_{4}^{3-}$ peaks at the wave number $1030 \mathrm{~cm}^{-1}$ which indicate the formation of the apatite-like phase is lower for blends with Sr mainly for blends 7.5 and $10 \mathrm{wt} \%$ BG- $1 \mathrm{wt} \%$ Sr after 1 day in SBF compared to Srfree ones. This showed that the strontium presence did not inhibit the formation of calcium phosphate layer but retarded its precipitation rate $^{41}$.

Figure 6 shows the XRD patterns of blends based on homogeneous calcium aluminate cement $(\mathrm{CH})$ containing different contents of bioactive glass (BG) and $1 \mathrm{wt} \%$ strontium (Sr) before and after soaking in SBF solution for 1 and 15 days.

After soaking in SBF, the blends present the presence of gibbsite $\left(\mathrm{Al}(\mathrm{OH})_{3}\right)$, and mainly evidence of the formation of crystalline calcium carbonate. In recent years, $\mathrm{CaCO}_{3}$ synthesis has been studied in detail due to its orthopedic, drug, and biomedical applications. Spherical $\mathrm{CaCO}_{3}$ particles presented fast penetration into human fibroblasts and did not show any cytotoxicity ${ }^{42}$. The identification of the precipitated calcium phosphate phase cannot be done with precision possibly because it is an amorphous phase.

The results of qualitative analysis of cell viability in pre-osteoblastic cell cultures exposed to the blends extracts for 72 hours are shown in Figure 7. Viable cells were labeled with green fluorescence, whereas dead cells were labeled with red fluorescence. A predominance of viable cells was detected in all experimental groups. In the comparison between groups of the same concentration, in $12.5 \%, 25 \%$ and $50 \%$, a slight drop in cell density could be noted in the $\mathrm{CH}$ and $\mathrm{CH}-10 \mathrm{BG}$ groups, while the other groups showed cell densities similar to the control.

Viability/cytotoxicity were also quantitatively assessed through mitochondrial activity after 48 and 72 hours of exposure to blends extracts, using the MTT colorimetric assay, as shown in Figure 8. After 48 hours of exposure, similar levels of cell viability were detected in Control and all cement groups, regardless of the concentration used (Kruskal Wallis/SNK; $\mathrm{p}>0.05$ ). 
Table 1. EDX analyses of the blend's surfaces before and after the interaction with SBF for 1, 7 and 15 days.

\begin{tabular}{|c|c|c|c|c|c|}
\hline Chemical composition (wt\%) & $\mathrm{O}$ & $\mathrm{Al}$ & $\mathrm{Si}$ & $\mathrm{P}$ & $\mathrm{Ca}$ \\
\hline $\mathrm{CH}$ & $57.3 \pm 0.5$ & $20.2 \pm 0.8$ & - & - & $11.3 \pm 0.7$ \\
\hline $\mathrm{CH}-1$ day & $58.6 \pm 0.4$ & $16.0 \pm 1.4$ & - & $1.2 \pm 0.2$ & $12.8 \pm 1.3$ \\
\hline $\mathrm{CH}-7$ days & $62.1 \pm 2.5$ & $21.2 \pm 2.7$ & - & $0.8 \pm 0.1$ & $8.3 \pm 1.8$ \\
\hline CH-15 days & $57.6 \pm 1.1$ & $3.3 \pm 0.6$ & - & $9.3 \pm 0.2$ & $21.0 \pm 0.9$ \\
\hline $\mathrm{CH}-5 \mathrm{BG}$ & $51.3 \pm 0.7$ & $18.6 \pm 0.4$ & $3.2 \pm 0.3$ & $0.3 \pm 0.1$ & $12.3 \pm 0.2$ \\
\hline CH-5BG-1 day & $61.9 \pm 0.5$ & $12.0 \pm 0.4$ & $2.2 \pm 0.2$ & $2.9 \pm 0.4$ & $21.1 \pm 0.7$ \\
\hline CH-5BG-7 days & $60.0 \pm 0.3$ & $1.4 \pm 0.4$ & $0.4 \pm 0.2$ & $13.5 \pm 0.2$ & $24.8 \pm 0.2$ \\
\hline CH-5BG-15 days & $62.2 \pm 0.8$ & $3.4 \pm 1.5$ & $1.7 \pm 0.2$ & $11.3 \pm 0.2$ & $21.4 \pm 0.8$ \\
\hline $\mathrm{CH}-7.5 \mathrm{BG}$ & $62.9 \pm 0.3$ & $24.3 \pm 0.2$ & $0.6 \pm 0.1$ & - & $12.5 \pm 0.2$ \\
\hline CH-7.5BG-1 day & $59.3 \pm 2.2$ & $3.2 \pm 1.8$ & $0.6 \pm 0.1$ & $12.7 \pm 1.6$ & $24.2 \pm 2.4$ \\
\hline CH-7.5BG-7 days & $62.3 \pm 0.7$ & $11.2 \pm 0.9$ & $0.6 \pm 0.2$ & $7.6 \pm 0.5$ & $18.3 \pm 0.9$ \\
\hline CH-7.5BG-15 days & $61.4 \pm 1.1$ & $6.3 \pm 0.9$ & $0.4 \pm 0.1$ & $10.8 \pm 0.4$ & $21.1 \pm 0.7$ \\
\hline $\mathrm{CH}-10 \mathrm{BG}$ & $56.1 \pm 0.8$ & $26.1 \pm 0.6$ & $0.8 \pm 0.1$ & $0.5 \pm 0.1$ & $16.5 \pm 0.5$ \\
\hline CH-10BG-1 day & $68.8 \pm 1.2$ & $10.0 \pm 0.3$ & $3.4 \pm 0.2$ & $4.1 \pm 0.3$ & $13.8 \pm 0.9$ \\
\hline CH-10BG-7 days & $63.9 \pm 0.5$ & $0.3 \pm 0.1$ & $0.3 \pm 0.1$ & $13.5 \pm 0.2$ & $22.2 \pm 0.3$ \\
\hline CH-10BG-15 days & $58.1 \pm 1.2$ & $2.6 \pm 0.3$ & $1.0 \pm 0.2$ & $12.6 \pm 0.4$ & $25.7 \pm 0.7$ \\
\hline $\mathrm{CH}-5 \mathrm{BG} / \mathrm{Sr}$ & $59.6 \pm 1.4$ & $22.8 \pm 1.6$ & $3.5 \pm 0.6$ & $0.3 \pm 0.2$ & $13.9 \pm 0.8$ \\
\hline CH-5BG/Sr-1 day & $60.3 \pm 0.5$ & $15.6 \pm 1.4$ & $7.5 \pm 1.3$ & $1.0 \pm 0.2$ & $14.9 \pm 0.4$ \\
\hline $\mathrm{CH}-5 \mathrm{BG} / \mathrm{Sr}-7$ days & $66.8 \pm 1.7$ & $10.4 \pm 1.1$ & $7.0 \pm 1.7$ & $3.6 \pm 0.5$ & $11.0 \pm 1.0$ \\
\hline CH-5BG/Sr-15 days & $58.8 \pm 0.4$ & $4.6 \pm 0.8$ & $5.3 \pm 0.6$ & $10.2 \pm 0.7$ & $19.7 \pm 0.6$ \\
\hline $\mathrm{CH}-7.5 \mathrm{BG} / \mathrm{Sr}$ & $62.5 \pm 0.9$ & $21.8 \pm 1.0$ & $1.3 \pm 0.4$ & $0.3 \pm 0.2$ & $14.1 \pm 0.4$ \\
\hline CH-7.5BG/Sr-1 day & $65.1 \pm 1.3$ & $2.5 \pm 0.5$ & $0.5 \pm 0.2$ & $11.5 \pm 0.3$ & $21.5 \pm 1.0$ \\
\hline CH-7.5BG/Sr-7 days & $62.1 \pm 0.1$ & $2.7 \pm 0.5$ & $0.2 \pm 0.1$ & $12.8 \pm 0.2$ & $23.7 \pm 0.6$ \\
\hline CH-7.5BG/Sr-15 days & $57.8 \pm 2.5$ & $1.6 \pm 0.5$ & $0.4 \pm 0.1$ & $13.8 \pm 0.5$ & $25.5 \pm 2.3$ \\
\hline $\mathrm{CH}-10 \mathrm{BG} / \mathrm{Sr}$ & $59.7 \pm 1.0$ & $22.5 \pm 0.4$ & $0.9 \pm 0.2$ & $0.3 \pm 0.1$ & $16.0 \pm 0.9$ \\
\hline $\mathrm{CH}-10 \mathrm{BG} / \mathrm{Sr}-1$ day & $67.4 \pm 1.1$ & $15.7 \pm 0.8$ & $2.8 \pm 0.2$ & $1.8 \pm 0.6$ & $11.3 \pm 0.6$ \\
\hline CH-10BG/Sr-7 days & $62.7 \pm 1.5$ & $3.6 \pm 0.4$ & $0.2 \pm 0.1$ & $11.2 \pm 0.3$ & $22.0 \pm 0.5$ \\
\hline CH-10BG/Sr-15 days & $61.1 \pm 1.0$ & $4.2 \pm 0.9$ & $0.5 \pm 0.1$ & $10.6 \pm 0.4$ & $23.0 \pm 0.5$ \\
\hline
\end{tabular}
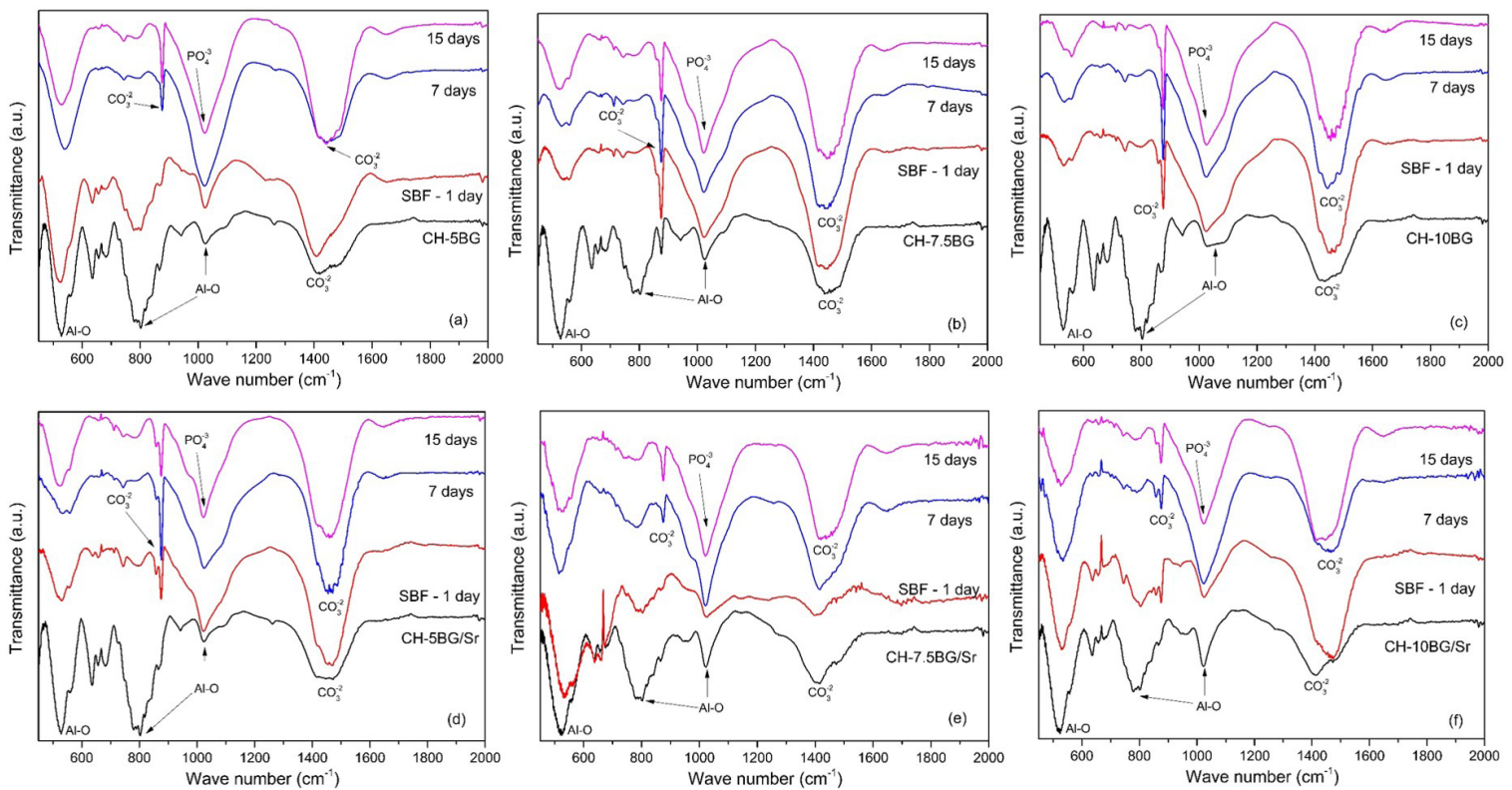

Figure 5. FTIR spectra for blends based on homogeneous calcium aluminate cement $(\mathrm{CH})$ containing different contents of bioactive glass (BG) and $1 \mathrm{wt} \%$ strontium (Sr), without or with SBF treatment for 1, 7 and 15 days. 
a- $\mathrm{Al}(\mathrm{OH})_{3} 012-0460$ b- $\mathrm{CaCO}_{3} 025-0127$ c- $\mathrm{CaCO}_{3} 033-0268$
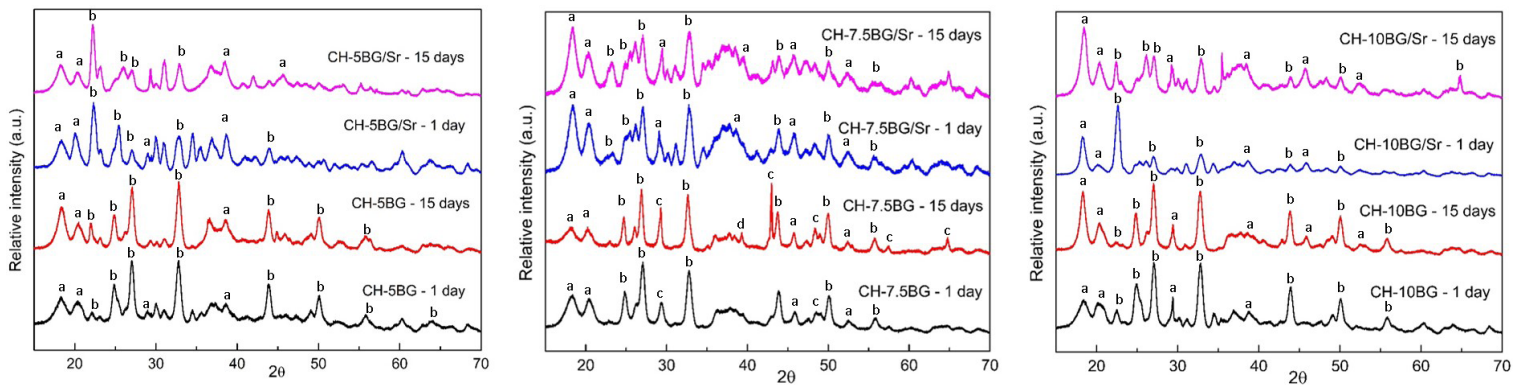

Figure 6. XRD patterns for blends based on homogeneous calcium aluminate cement $(\mathrm{CH})$ containing different contents of bioactive glass (BG) and $1 \mathrm{wt} \%$ strontium (Sr), without or with SBF treatment for 1 and 15 days.

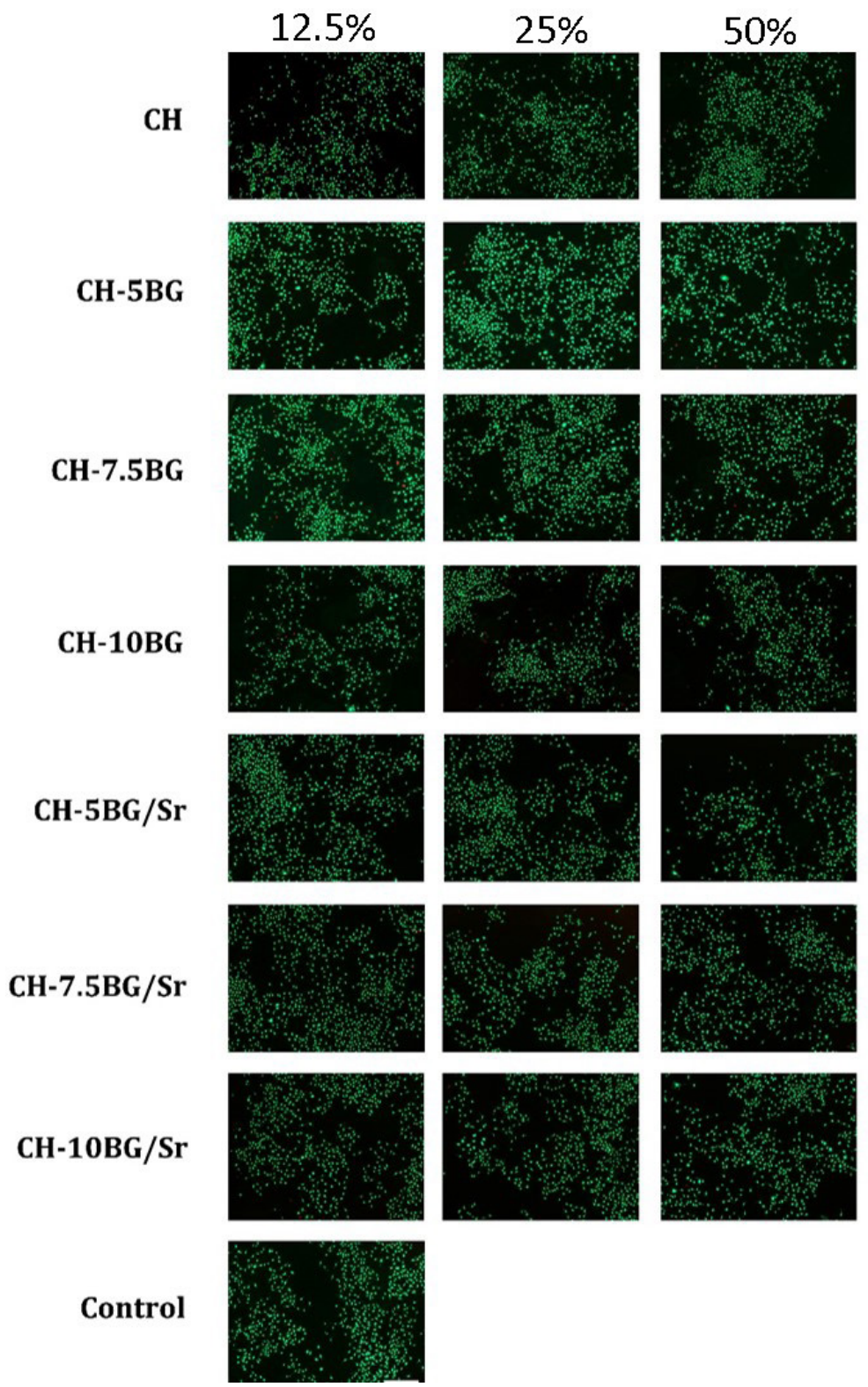

Figure 7. Cell viability in culture of pre-osteoblastic cells exposed to extracts of compositions based on calcium aluminate cement $(\mathrm{CH})$ containing different contents of bioactive glass $(\mathrm{BG})$ and strontium $(\mathrm{Sr})$ in concentrations of $12.5 \%, 25 \%$ and $50 \%$ or in their absence (control) for 3 days. Green marking indicates viable cells and red, dead cells. Scale bar $=200 \mu \mathrm{m}$. 
After 72 hours, the MTT assay revealed no statistical differences for the values of cell viability among groups at concentrations of $12.5 \%$ and $25 \%$ (Kruskal Wallis/SNK; $\mathrm{p}>0.05$ ). However, at the $50 \%$ concentration, significant differences were detected between the cell viability values obtained in the groups: Control $>\mathrm{CH}-10 \mathrm{BG} / \mathrm{Sr}>\mathrm{CH}-7.5 \mathrm{BG}$ $=\mathrm{CH}>\mathrm{CH}-10 \mathrm{BG}=\mathrm{CH}-7.5 \mathrm{BG} / \mathrm{Sr}=\mathrm{CH}-5 \mathrm{BG} / \mathrm{Sr}=\mathrm{CH}-5 \mathrm{BG}$ (Kruskal Wallis/SNK; $<<0.05$ ).

The decrease in cell viability observed in cultures exposed to the $50 \%$ dilution of the culture medium could be explained, at least in part, by the increase in the concentration of calcium and hydroxyl ions in the culture medium, resulting in an increase in $\mathrm{pH}$ of the cellular microenvironment; indeed, very high levels of calcium can promote cell death by apoptosis or necrosis ${ }^{43}$.

Different letters between the samples $(50 \%, 72 \mathrm{~h})$ indicate a significant difference between groups at the same concentration (Kruskal Wallis/SNK, $\mathrm{p}<0.05$ ). For all other results, there was no statistical difference.

Figures 9 and 10 show the results obtained for the qualitative assessment of ALP activity after 7 days and mineralized nodule formation on the 14 th, respectively.

\section{Cell Viability - 48 hours}

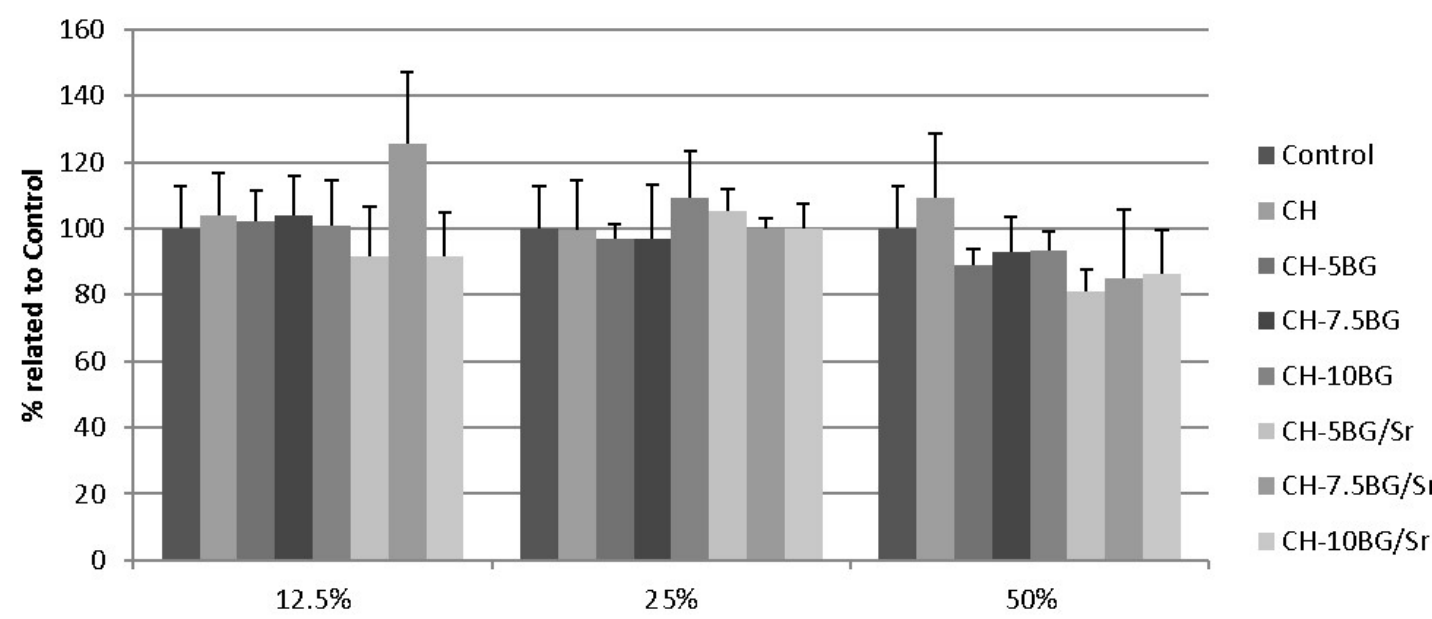

$\%$ extract in culture medium

\section{Cell Viability - 72 hours}

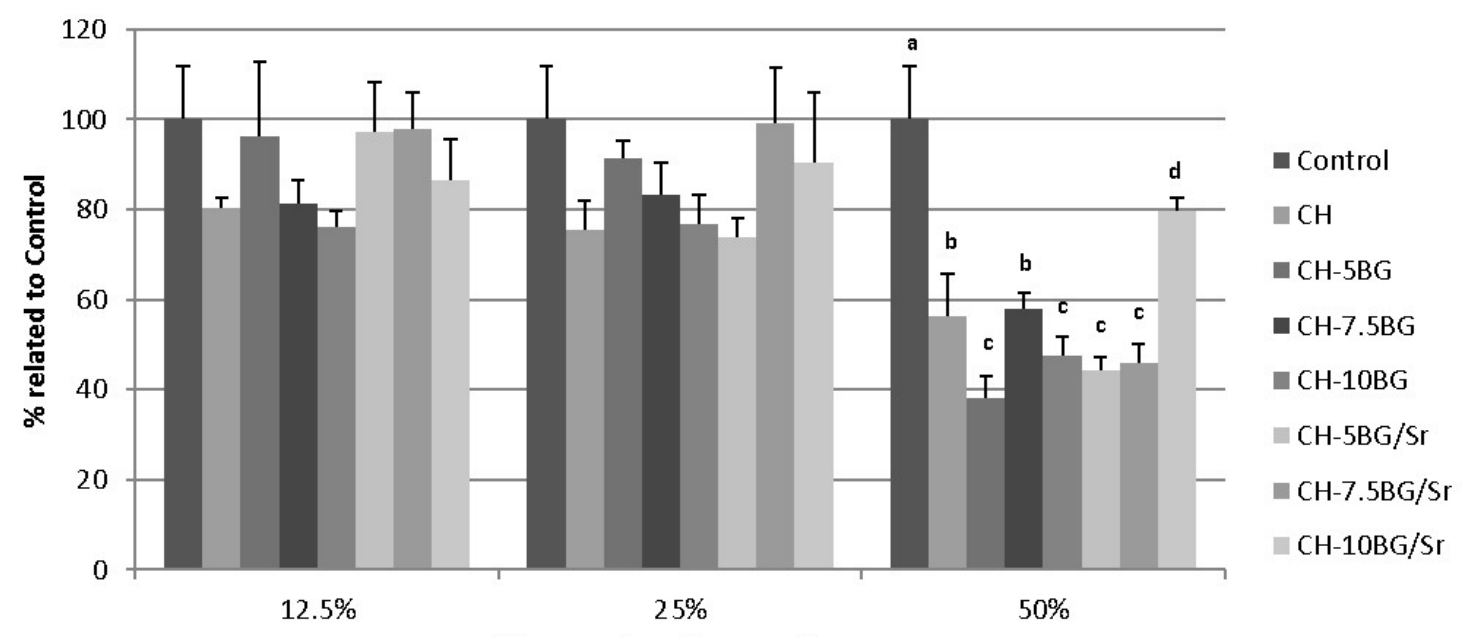

$\%$ extract in culture medium

Figure 8. Cell viability test (MTT) in culture of pre-osteoblastic cells exposed to extracts of compositions based on calcium aluminate cement $(\mathrm{CH})$ containing different contents of bioactive glass $(\mathrm{BG})$ and strontium $(\mathrm{Sr})$ in concentrations of $12.5 \%, 25 \%$ and $50 \%$ or in their absence (control) for 48 and 72 hours. Different letters between the samples $(50 \%, 72 \mathrm{~h})$ indicate a significant difference between groups at the same concentration (Kruskal Wallis/SNK, $\mathrm{p}<0.05$ ). For all other results there was no statistical difference. 

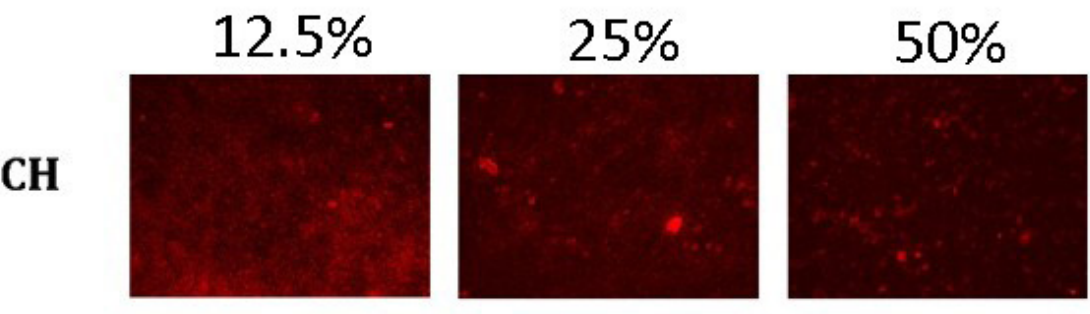

CH-5BG
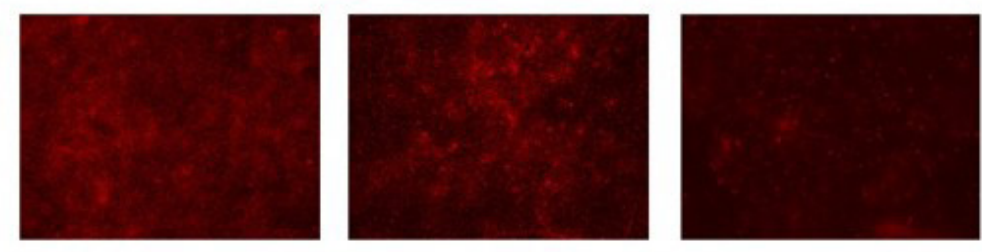

CH-7.5BG
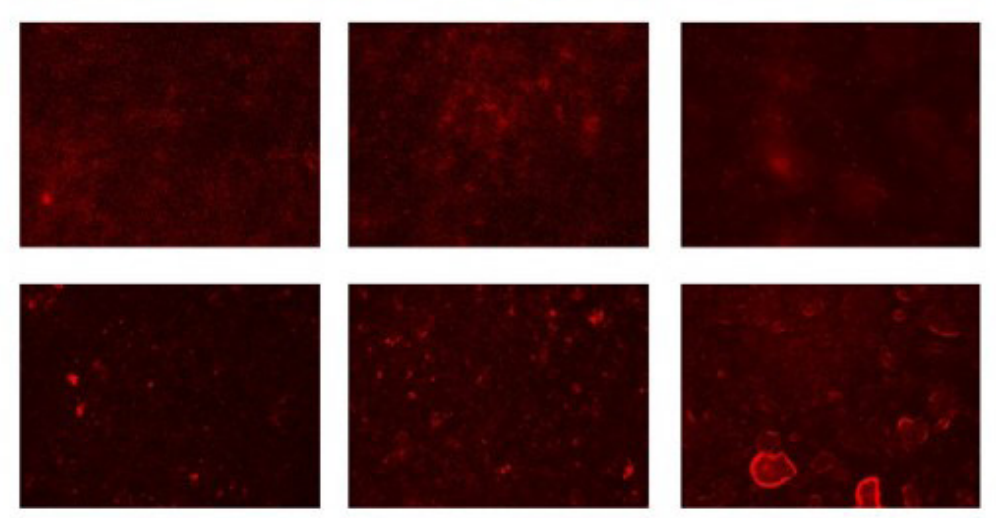

CH-10BG

CH-5BG/Sr
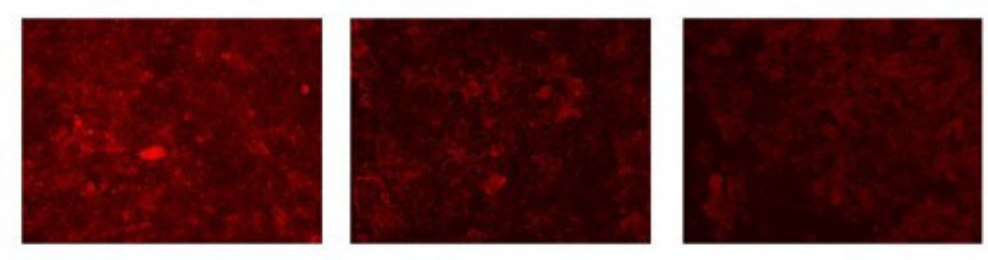

CH-7.5BG/Sr
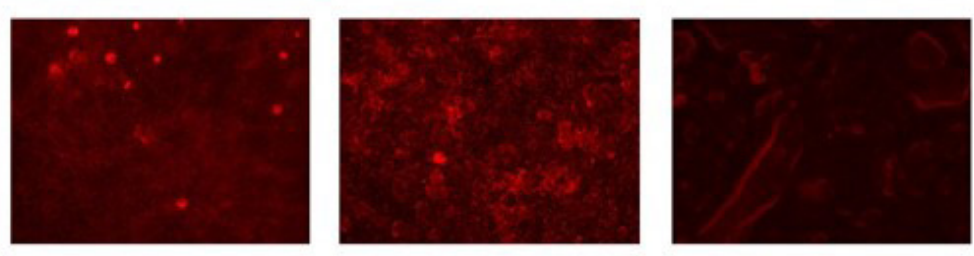

$\mathrm{CH-10BG/Sr}$
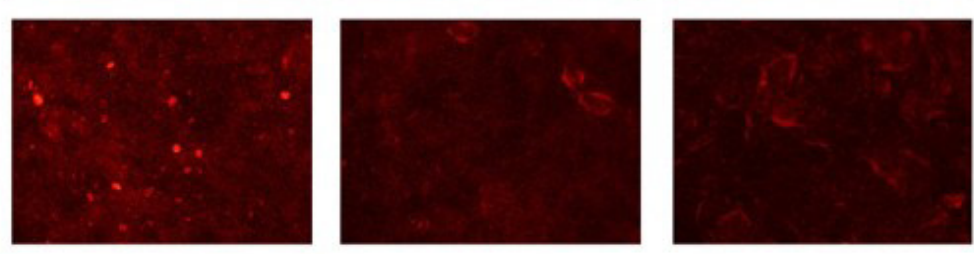

\section{Control}

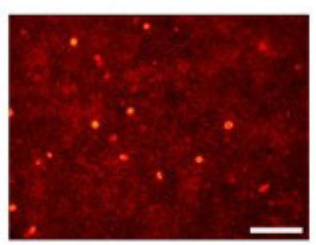

Figure 9. Activity of the alkaline phosphatase (ALP) enzyme in culture of pre-osteoblastic cells exposed to extracts of compositions based on calcium aluminate cement $(\mathrm{CH})$ containing different contents of bioactive glass $(\mathrm{BG})$ and strontium $(\mathrm{Sr})$ in concentrations of $12.5 \%$, $25 \%$ and $50 \%$ or in their absence (control) for 7 days. Scale bar $=200 \mu \mathrm{m}$. 


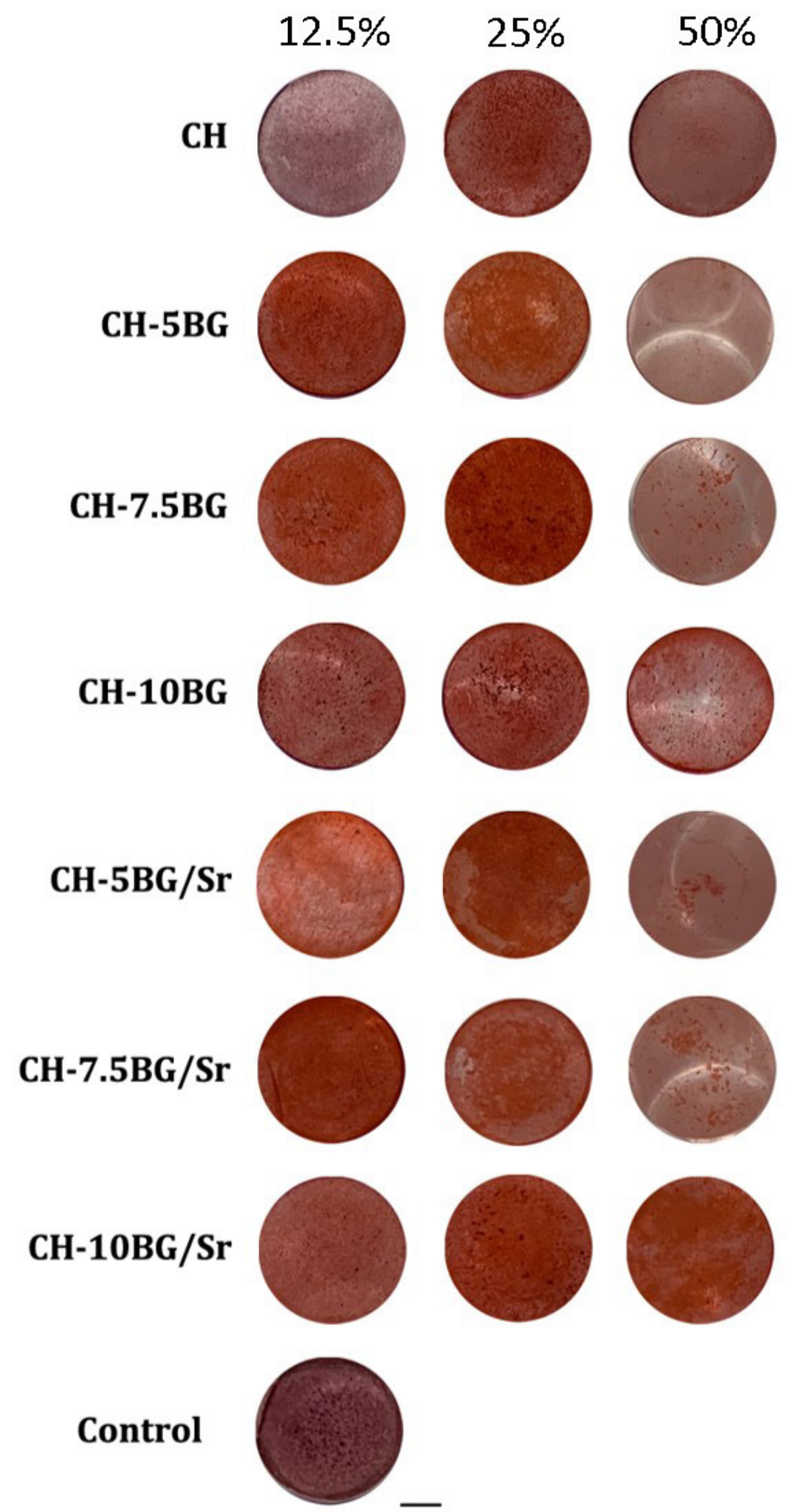

Figure 10. Macroscopic aspects of alizarin red marking in osteoblastic cultures of the MC3T3-E1 strain exposed to extracts of compositions based on calcium aluminate cement $(\mathrm{CH})$ containing different contents of bioactive glass $(\mathrm{BG})$ and strontium $(\mathrm{Sr})$ in concentrations of $12.5 \%, 25 \%$ and $50 \%$ or in their absence (control) for 14 days. Scale bar $=200 \mu \mathrm{m}$. 


\section{Mineralization - 14 days}

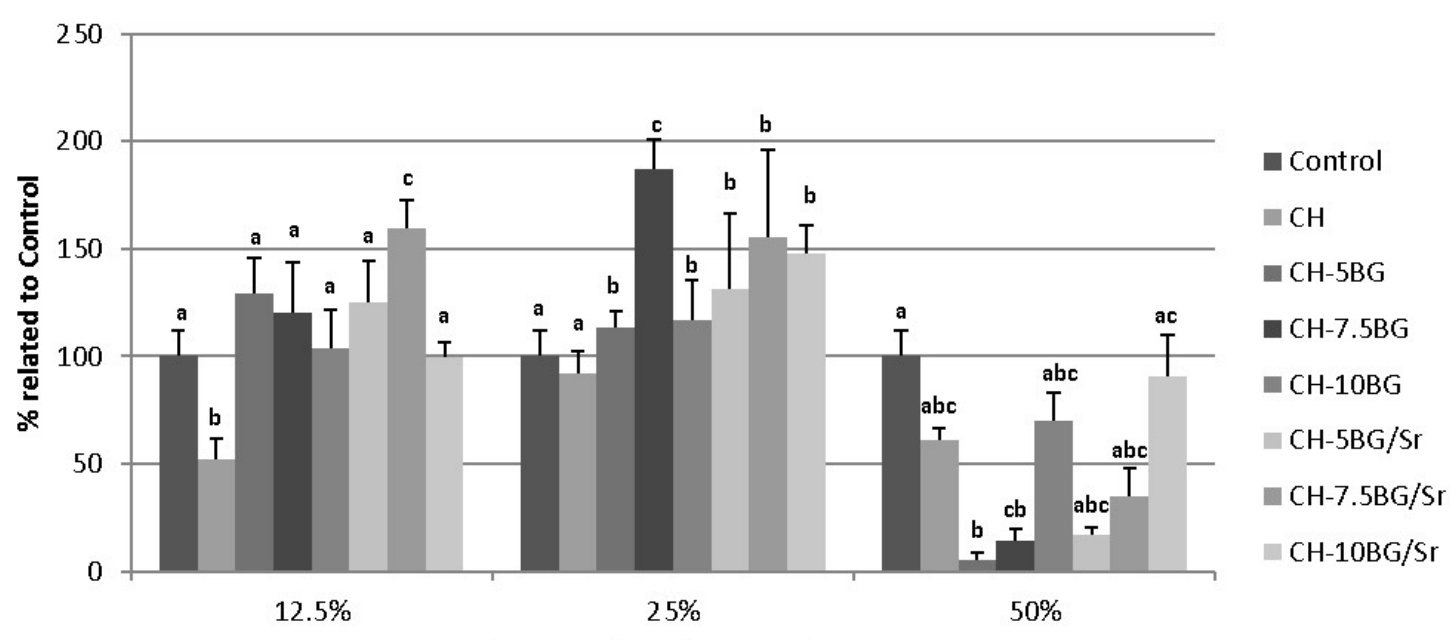

$\%$ extract in culture medium

Figure 11. Biochemical quantification of mineralization in osteoblastic cultures of the MC3T3-E1 strain exposed to extracts of compositions based on calcium aluminate cement $(\mathrm{CH})$ containing different contents of bioactive glass (BG) and strontium ( $\mathrm{Sr}$ ) in concentrations of $12.5 \%, 25 \%$ and $50 \%$ for 14 days. Different letters between the samples indicate a significant difference between groups at the same concentration (Kruskal Wallis / SNK, p <0.05).

The biochemical quantification of mineralization on the 14th is shown in Figure 11.

From the qualitative assessment of ALP activity by Fast Red labeling, positive colonies for alkaline phosphatase enzyme activity were found in all experimental groups exposed to cement extracts, presenting macroscopic aspects similar to those of the control (Figure 9).

At the end of 14 days, the marking of calcium deposits by alizarin red revealed significant differences for the osteogenic potential of the different cements tested (Figure 10). The morphological aspects revealed positive areas for calcium deposits in all cement groups at the concentrations of $12.5 \%$ and $25 \%$, particularly for $\mathrm{CH}-7.5 \mathrm{BG} / \mathrm{Sr}(12.5 \%)$ and $\mathrm{CH}-7.5 \mathrm{BG}(25 \%)$. At $50 \%$, there was a drop in alizarin red labeling in all cement groups, except by $\mathrm{CH}-10 \mathrm{BG} / \mathrm{Sr}$, which maintained macroscopic aspects similar to those of the control.

In a quantitative analysis of the extracellular matrix mineralization test (Figure 11), it was revealed that for the concentration of $12.5 \%$ : $\mathrm{CH}-7.5 \mathrm{BG} / \mathrm{Sr}>\mathrm{CH}-5 \mathrm{BG}=\mathrm{CH}-$ $5 \mathrm{BG} / \mathrm{Sr}=\mathrm{CH}-7.5 \mathrm{BG}=\mathrm{CH}-10 \mathrm{BG}=\mathrm{Control}=\mathrm{CH}-10 \mathrm{BG} / \mathrm{Sr}$ $>\mathrm{CH}$ (Kruskal Wallis/SNK; $\mathrm{p}<0.05$ ). At 25\%: $\mathrm{CH}-7.5 \mathrm{BG}$ $>\mathrm{CH}-7.5 \mathrm{BG} / \mathrm{Sr}=\mathrm{CH}-10 \mathrm{BG} / \mathrm{Sr}=\mathrm{CH}-5 \mathrm{BG} / \mathrm{Sr}=\mathrm{CH}-10 \mathrm{BG}$ $=\mathrm{CH}-5 \mathrm{BG}>\mathrm{Control}=\mathrm{CH}($ Kruskal Wallis $/ \mathrm{SNK} ; \mathrm{p}<0.05)$. At $50 \%$ : $\mathrm{CH}-10 \mathrm{BG} / \mathrm{Sr}=\mathrm{Control}=\mathrm{CH}-10 \mathrm{BG}=\mathrm{CH}>\mathrm{CH}-$ $7.5 \mathrm{BG} / \mathrm{Sr}>\mathrm{CH}-5 \mathrm{BG} / \mathrm{Sr}=\mathrm{CH}-7.5 \mathrm{BG}>\mathrm{CH}-5 \mathrm{BG}$ (Kruskal Wallis/SNK; $\mathrm{p}<0.05$ ).

The findings on cell differentiation revealed that all blends allowed the development of the osteoblastic phenotype, since the cultures were positive for ALP activity and matrix mineralization deposits. From the mineralization data, it was observed that the inclusion of BG-58S and $\mathrm{Sr}$ in the $\mathrm{CH}$ promoted the osteogenesis process, particularly for $\mathrm{CH}-7.5 \mathrm{BG}$, $\mathrm{CH}-7.5 \mathrm{BG} / \mathrm{Sr}$ and $\mathrm{CH}-10 \mathrm{BG} / \mathrm{Sr}$ groups, with an increase in the formation of mineralized matrix compared with $\mathrm{CH}$.

It is known that when BG comes into contact with biological fluids, surface dissolution occurs and ions are released into the medium. Thus, the effects of these formulations on matrix mineralization could be related both to $\mathrm{Ca}^{2+}$ and to Sr. Small increase in the physiological levels of calcium has positive effects on osteoblastic differentiation ${ }^{44-47}$. In general, previous studies describe that the presence of $\mathrm{Sr}$, both in vivo and in vitro, promotes the formation of bone nodules, increased bone mass and accelerated bone callus consolidation ${ }^{48-50}$. The benefit caused by the addition of $\mathrm{Sr}$ to the formulations could be explained, at least in part, by the presence of calcium-sensing receptor in osteoblasts. These receptors can be activated by divalent ions, such as calcium and strontium, resulting in the activation of bone metabolism ${ }^{48,51-55}$.

\section{Conclusions}

The present study evaluates the influence of $\mathrm{BG}$ addition on some properties of homogeneous calcium aluminate cement $(\mathrm{CH})$. The addition of $\mathrm{BG}$ to $\mathrm{CH}$ has little effect on the theoretical density of pure $\mathrm{CH}$ independently of the content of BG. On the other hand, the addition of BG to $\mathrm{CH}$ influences mainly its mechanical properties. The mechanical strength of $\mathrm{CH}$ increases with the $\mathrm{BG}$ addition due to improve particle packing what decreases the apparent porosity before SBF treatment $(10 \mathrm{wt} \% \mathrm{BG})$. However, the addition of higher levels of BG led to a reduction in microhardness. Thus, it can be suggested that the blend $7.5 \mathrm{wt} \%$ of BG is the most 
promising resulting in lower apparent porosity and pore size due to the presence of precipitates on the surface of the materials in SBF. In addition, the blends $7.5 \mathrm{wt} \% \mathrm{BG}$ without and with $\mathrm{Sr}$ were more bioactive than $\mathrm{CH}$ due to the precipitation of a highly soluble amorphous phase from 1 day in SBF as confirmed by means of SEM/EDX. FTIR analyses indicate the formation the apatite-like phase by means of increase of intensity of the $\mathrm{PO}_{4}^{3-}$ peaks after SBF treatment and that the strontium presence does not inhibit the formation of calcium phosphate layer but retards its precipitation rate. However, crystalline calcium carbonate phase is mainly identified by DRX because probably the precipitated calcium phosphate phase is an amorphous phase. All blends allow the development of the osteoblastic phenotype, since the cultures were positive for ALP activity and matrix mineralization deposits. The formation of mineralized matrix increases due to the inclusion of $\mathrm{BG}$ and $\mathrm{Sr}$ in the $\mathrm{CH}$ promoting the osteogenesis process.

\section{Acknowledgements}

The authors would like to acknowledge the Brazilian Research Foundations: National Council for Scientific and Technological Development - CNPq (303149/2018$3)$, FAPESP (2019/15960-6), Finep (01.13.0275.00 and 01.18.0053.00) and University of Vale do Paraíba, SP, Brazil for supporting this research.

\section{References}

1. Aslankoohi N, Mondal D, Rizkalla AS, Mequanint K. Bone repair and regenerative biomaterials: towards recapitulating the microenvironment. Polymers (Basel). 2019;11(9):1437-68.

2. Vasconcellos LMR, Camporês KL, Abdala JMA, Vieira MN, Oliveira IR. Biological and microbiological behavior of calcium aluminate cement-based blend for filling of bone defects. J Mater Sci Mater Med. 2020;31(10):1-10.

3. Wang W, Yeung KWK. Bone grafts and biomaterials substitutes for bone defect repair: a review. Bioact Mater. 2017;2(4):22447.

4. Raut HK, Das R, Liu Z, Liu X, Ramakrishma S. Biocompatibility of biomaterials for tissue regeneration or replacement. Biotechnol J. 2020;15(12):145-51.

5. Vicuna DLNG, Grancianinov KJS, Dos Santos KW, Ortega FS, Mello DCR, Vasconcellos LMR, et al. Scaffold's production based on calcium aluminate blends and their biological properties. Res Biomed Eng. 2019;35(2):131-41.

6. Oliveira IR, Barbosa AM, Gracianov KJ, Origo FD, Santos KW, Leite PMCM, et al. Surface properties of calcium aluminate cement blends for bone repair applications. Ceram Int. 2020;46(9):14241-51.

7. Hermansson L. Nanostructural chemically bonded Ca-Aluminate based bioceramics. In: Pignatello R, editor. Biomaterials Physics and Chemistry. London: IntechOpen; 2011. p. 47-74.

8. Loof J. Calcium-aluminate as biomaterial: synthesis, design and evaluation (thesis). Uppsala: Faculty of Science and Technology, University, Sweden; 2008.

9. Kopanda E, MacZura G. Production processes properties and applications for calcium aluminate cements. In Hart LD. Alumina chemicals science technology handbook. Columbus: American Ceramic Society; 1990.

10. Oliveira IR, Andrade TL, Araujo KCML, Luz AP, Pandolfelli VC. Hydroxyapatite synthesis and the benefits of its blend with calcium aluminate cement. Ceram Int. 2016;42(5):2542-9.
11. Ravarian R, Moztarzadeh F, Solati MH, Rabiee SM, Khoshakhlagh $\mathrm{P}$, Tahriri M. Synthesis, characterization and bioactivity investigation of bioglass/hydroxyapatite composite. Ceram Int. 2010;36(6):291-7.

12. Balamurugan A, Balossier G, Kannan S, Michel J, Rebelo $\mathrm{AH}$, Ferreira JM. Development and in vitro characterization of sol-gel derived $\mathrm{CaO}-\mathrm{P}_{2} \mathrm{O}_{5}-\mathrm{SiO}_{2}-\mathrm{ZnO}$ bioglass. Acta Biomater. 2007;45(4):255-62.

13. Tengjiao Z, Huihui R, Ailing L, Bingchuan L, Caiyun C, Yanmei $\mathrm{D}$, et al. Novel bioactive glass based injectable bone cement with improved osteoinductivity and its in vivo evaluation. Sci Rep. 2017;34(7):3622-31.

14. Ghannam AE. Bone reconstruction: from bioceramics to tissue engineering. Journal Expert Rev. Med. Devices. 2005;34(2):87101.

15. Vergnol G, Ginsac N, Rivory P, Meille S, Chenal JM, Balvay $\mathrm{S}$, et al. In vitro and in vivo evaluation of a polylactic acidbioactive glass composite for bone fixation devices. J Biomed Mater Res B Appl Biomater. 2016;104(1):180-91.

16. Rezaei $Y$. Synthesis, characterization, and in vitro bioactivity of sol-gel-derived $\mathrm{SiO}_{2}-\mathrm{CaO}-\mathrm{P}_{2} \mathrm{O}_{5}-\mathrm{MgO}-\mathrm{SrO}$ bioactive glass. Synth React Inorg Met-Org Nano-Met Chem. 2014;44(5):692701.

17. Usuda K, Kono KI, Dote T, Watanabe M, Shimizu H, Tanimoto $\mathrm{Y}$, et al. An overview of boron, lithium, and strontium in human health and profiles of these elements in urine of Japanese. Environ Health Prev Med. 2007;12(6):231-7.

18. Querido W, Rossi AL, Farina M. The effects of strontium on bone mineral: a review on current knowledge and microanalytical approaches. Micron. 2016;80(5):122-34.

19. Morejón AL, Santos LA, Carrodeguas RG. Influence of mixing liquid on the properties of calcium aluminate cement. Key Eng Mater. 2009;39(7):241-4.

20. ISO: International Organization for Standardization. ISO 23317:2014. Implants for surgery - In vitro evaluation for apatite-forming ability of implant materials. Genebra: ISO.

21. Nakao M, Ozawa S, Yogo K, Miura H, Yamada K, Hosono $\mathrm{F}$, et al. Tolerance levels of mass density for $\mathrm{CT}$ number calibration in photon radiation therapy. J Appl Clin Med Phys. 2019;20(6):45-52.

22. Bala Y, Kohles J, Recker RR, Boivin G. Oral ibandronate in postmenopausal osteoporotic women alters micromechanical properties independently of changes in mineralization. Calcif Tissue Int. 2013;92(1):6-14.

23. Havaldar R, Pilli SC, Putti BB. Insights into effects of tensile and compressive loadings on human femur done. Adv Biomed Res. 2014;25(5):101-11.

24. Cesar R, Leivas TP, Pereira CAM, Boffa RS, Guarniero R, Reiff RBM, et al. Axial compressive strengh of human vertebral trabecular bonés classified as normal, osteopenic and osteorotic by quantitative ultrassonometry of calcaneus. Res Biomed Eng. 2017;33(2):91-7.

25. Oliveira IR, Andrade TL, Parreira RM, Jacobovitz M, Pandolfelli VC. Characterization of calcium aluminate cement phases when in contact with simulated body fluid. Mater Res. 2015;18(2):382-9.

26. Oliveira IR, Vieira GV, Santos KW, Raniero LJ, Castro-Raucci LM, Oliveira PT, et al. Improving the radiopacity of calcium aluminate cement based blends. Mater Res. 2018;21(2):1-11.

27. Seabra DEA. Studies of bioactivity of zinc oxide nanostructures [dissertation]. Portugal: Aveiro University; 2013.

28. Kaur G, Pickrell G, Sriranganathan N, Kumar V, Homa D. Review and the state of the art: sol-gel and melt quenched bioactive glasses for tissue engineering. J. Biomed. Mater. Res. Parte B. 2016;104(6):1248-75.

29. Avram D, Ungureanu D, Angelescu N, Barroso de Aguia J. A comparative study on the properties of potentially bioactive glasses obtained by sol-gel technique and by melting mixtures of 
oxides. Scientific Bulletin of Valahia University. 2017;15(13):1824.

30. Wu C, Zhang Y, Ke X, Xie Y, Zhu H, Crawford R, et al. Bioactive mesopore-glass microspheres with controllable protein delivery properties by biomimetic surface modification. J Biomed Mater Res A. 2010;95A:476-85.

31. Bui XV, Oudadesse H, Le Gal Y, Mostafa A, Cathelineau G. Microspheres of chitosan-bioactive glass for application in orthopedic surgery. In vitro experiment. Recent Researches in Modern Medicine. 2011;17(3):359-67.

32. Balamurugan A, Sockalingumb G, Michela J, Fauréa J, Banchetc V, Worthama L, et al. Synthesis and characterisation of sol gel derived bioactive glass for biomedical applications. Mater Lett. 2006;60(5):3752-7.

33. Islam MT, Felfel RM, Abou Neel EA, Grant DM, Ahmaed I, Hossain KMZ. Bioactive calcium phosphate-based glasses and ceramics and their biomedical applications: a review. J Tissue Eng. 2017;38(7):1-16.

34. García-Álvarez G, Escobedo-Bocardo JC, Cortés-Hernández DA, Almanza-Robles JM. Bioactivity and mechanical properties of scaffolds based on calcium aluminate and bioactive glass. Int J Mater Res. 2019;110(4):343-50.

35. Maitra S, Bose S, Bandyopadhyay N, Roychoudhury A. Dehidratation kinetics of calcium aluminate cement hydrate under non-isothermal conditions. Ceram Int. 2005;31(3):371-4.

36. Nariyal R, Kothari P, Bisht B. FTIR measurements of $\mathrm{SiO}_{2}$ glass prepared by sol-gel technique. Chem Sci Trans. 2014;56(3):10646.

37. Rezaei Y. Synthesis, characterization, and in vitro bioactivity of sol-gel-derived $\mathrm{SiO}_{2}-\mathrm{CaO}-\mathrm{P}_{2} \mathrm{O}_{5}-\mathrm{MgO}-\mathrm{SrO}$ bioactive glass. Synth React Inorg Met-Org Nano-Met Chem. 2014;44(3):692701.

38. Qiu Q, Ducheyne P, Ayyaswamy PA. New bioactive, degradable composite microspheres as tissue engineering substrates. J Biomed Mater Res. 2000;52(8):66-76.

39. Maçon ALB, Lee S, Jones JR. Synthesis and dissolution behaviour of $\mathrm{CaO} / \mathrm{SrO}$-containing sol-gel derived $58 \mathrm{~S}$ glasses. J Mater Sci. 2017;52(6):8858-70.

40. Luz GM, Mano JF. Preparation and characterization of bioactive glass nanoparticles prepared by sol-gel for biomedical applications. Nanotechnology. 2011;22(4):1-11.

41. Ereiba KM, Abd Raboh AS, Mostafa AG. Characterization of some bioactive glasses based on $\mathrm{SiO}_{2}-\mathrm{CaO}-\mathrm{P}_{2} \mathrm{O}_{5}-\mathrm{SrO}$ quaternary system prepared by sol-gel method. Nat Sci. 2014;12(5):97105.
42. Oral ÇM, Ercan B. Influence of $\mathrm{pH}$ on morphology, size and polymorph of room temperature synthesized calcium carbonate particles. Powder Technol. 2018;339(12):781-8.

43. Orrenius S, Zhivotovsky B, Nicotera P. Regulation of cell death: the calcium-apoptosis link. Nat Rev Mol Cell Biol. 2003;4(7):552-65.

44. Castro-Raucci LM, Oliveira IR, Teixeira LN, Rosa AL, Oliveira PT, Jacobovitz M. Effects of a novel calcium aluminate cement on the early events of the progression of osteogenic cell cultures. Braz Dent J. 2011;22(2):99-104.

45. Dvorak MM, Riccardi D. $\mathrm{Ca}^{2+}$ as an extracellular signal in bone. Cell Calcium. 2004;35(3):249-55.

46. Narita H, Itoh S, Imazato S, Yoshitake F, Ebisu S. An explanation of the mineralization mechanism in osteoblasts induced by calcium hydroxide. Acta Biomater. 2010;6(2):586-90.

47. Matsumoto S, Hayashi M, Suzuki Y, Suzuki N, Maeno M, Ogiso B. Calcium ions released from mineral trioxide aggregate convert the differentiation pathway of $\mathrm{C} 2 \mathrm{C} 12$ cells into osteoblast lineage. J Endod. 2013;39(1):68-75.

48. Almeida MM, Nani EP, Teixeira LN, Peruzzo DC, Joly JC, Napimoga $\mathrm{MH}$, et al. Strontium ranelate increases osteoblast activity. Tissue Cell. 2016;48(3):183-8.

49. Ammann P, Shen V, Robin B, Mauras Y, Bonjour JP, Rizzoli R. Strontium ranelate improves bone resistance by increasing bone mass and improving architecture in intact female rats. J Bone Miner Res. 2004;19(12):2012-20.

50. Li YF, Luo E, Feng G, Zhu SS, Li JH, Hu J. Systemic treatment with strontium ranelate promotes tibial fracture healing in ovariectomized rats. Osteoporos Int. 2010;21(11):1889-97.

51. Coulombe J, Faure H, Robin B, Ruat M. In vitro effects of strontium ranelate on the extracellular calcium-sensing receptor. Biochem Biophys Res Commun. 2004;323(4):1184-90.

52. Caverzasio J. Strontium ranelate promotes osteoblastic cell replication through at least two different mechanisms. Bone. 2008;42(6):1131-6.

53. Chattopadhyay N, Quinn SJ, Kifor O, Ye C, Brown EM. The calcium-sensing receptor $(\mathrm{CaR})$ is involved in strontium ranelate-induced osteoblast proliferation. Biochem Pharmacol. 2007;74(3):438-47.

54. Caudrillier A, Hurtel-Lemaire AS, Wattel A, Cournarie F, Godin C, Petit L, et al. Strontium ranelate decreases receptor activator of nuclear factor-KB ligand-induced osteoclastic differentiation in vitro: involvement of the calcium-sensing receptor. Mol Pharmacol. 2010;78(4):569-76.

55. Yamaguchi $\mathrm{T}$. The calcium-sensing receptor in bone. J Bone Miner Metab. 2008;26(4):301-11. 